\title{
Atomic force microscopy of food assembly: Structural and mechanical insights at the nanoscale and potential opportunities from other fields
}

\author{
Sameh Obeid, Fanny Guyomarc'h* \\ Science and Technology of Milk and Egg (STLO), National Research Institute for Agriculture, Food and Environment (INRAE), Agrocampus Ouest, 35000 Rennes, France
}

\section{A R T I C L E I N F O}

\section{Keywords:}

Food structure

Atomic force microscopy

Nanoscale imaging

Nanomechanics

\begin{abstract}
A B S T R A C T
The atomic force microscope (AFM) has opened access to the nanoscale observation of molecular and colloidal structures in aqueous media, and of their dynamics upon environmental changes. As a miniature force scanner, it furthermore allows the correlative mapping of mechanical properties at the nanoscale or precise indentation of individual structures. Soon after its invention in 1986, the AFM rapidly found increasing applications in soft matter physics, cellular biology, polymer science and microbiology. In spite of significant successes as early as the 90s, the growth of AFM application in the field of food science has been comparatively slower. This review points to the realizations and opportunities of AFM in showing the connections between the structural and mechanical properties of food's building blocks and of their assemblies. Possible transfers from other disciplines to food science are presented as suggestions for future applications.
\end{abstract}

\section{Food structures at the nanoscale: assemblies, interfaces,} dynamics

Many concepts of cell biology, physiology, material sciences or biophysics have been successfully passed on to food science, for a better understanding of food structures and functional properties. Food may indeed be considered as the successive disassembly and reassembly of building blocks extracted from agricultural resources, processed into edibles then eventually eaten and digested. Internal structures, shape, porosity or surface properties of the building blocks, as well as the tridimensional connections established between these blocks upon food processing will determine texture or the capacity of the macrostructure to entrap moisture, ligands or bacteria (Walstra, 2002). The three dimensional structure may vary with time or with environmental pressure, such as a change in temperature, pressure or $\mathrm{pH}$, and so will evolve the functional properties of foodstuff upon processing or storage. Surface phenomena are taking place at all boundaries of compartmented food structures, like particulate suspensions, porous gels, emulsions, foams or tissues. Food interfaces encompass a large range of complex two dimensional structures, from small surfactants to thin films of multilayered proteins, particulate objects to polar lipid membranes (Berton-Carabin, Sagis, \& Schroën, 2018; Dickinson, 2015). Reassembly events, transfers and biological reactions occur at food interfaces with dynamics from sec to hr to days (Berton-Carabin et al., 2018; Guo, Ye, Bellissimo, Singh, \& Rousseau, 2017; Marze, 2013;
Sadek et al., 2015). Similarly, a multiscale approach is essential to link local properties of the building block assemblies to the macroscopic properties of the food (Roos et al., 2016). Local protein concentration at the air/water interface can be as high as to induce a sol/gel transition and affect the properties of a foam (Pasquier et al., 2016). Fluctuations in the phase separation of polar lipids occur at the nano- or micrometer scale depending on composition and temperature, and affect the physical properties of membranes (Connell, Heath, Olmsted, \& Kisil, 2013; Veatch, 2007). Meanwhile, rheology or aging of protein gels may be inferred from scaling models based on the detailed characterization of the structure and connectivity of the colloidal building blocks (Mellema, van Opheusden, \& van Vliet, 2002; Tanaka \& Araki, 2007).

Since its invention in 1986 (Binnig, Quate, \& Gerber, 1986), the AFM has gained increasing attention from scientific communities in biological sciences, including food science. AFM can show a significantly greater spatial resolution than optical microscopes. Where super-resolution techniques overcome the diffraction limit down to $\sim 10 \mathrm{~nm}$ resolution, AFM can achieve nanometer detail in biological samples, which gives access to the observation of the building blocks of live objects at the molecular level (Dufrêne et al., 2017). AFM does not need labelling nor fixation of the sample. The only requirement is that objects are immobilized during raster scanning by the AFM probe. Furthermore, AFM can examine samples in ambient or liquid environments, at a wide range of temperatures relevant for biological or food samples (de sa Peixoto et al., 2015; Murthy, Guyomarc'h, \& Lopez,

\footnotetext{
* Corresponding author. UMR STLO 1253 INRAE-Agrocampus Ouest, 65 rue de Saint Brieuc, 35042 Rennes cedex, France.

E-mail address: fanny.guyomarc-h@inrae.fr (F. Guyomarc'h).
} 
2016a). Therefore, AFM has become a preferred imaging technique to implement multiscale approaches using various microscopy techniques (Bhatia, Husen, Ipsen, Bagatolli, \& Simonsen, 2014; Lopez, Cauty, \& Guyomarc'h, 2015; Wackerbarth, Schön, \& Bindrich, 2009). Dynamic events can be accessed by continuously imaging the same sample area while modifying the environment by, e.g., cooling or heating (Leonenko, Finot, Ma, Dahms, \& Cramb, 2004; Murthy et al., 2016a), acidifying (de sa Peixoto et al., 2015; Ouanezar, Guyomarc'h, \& Bouchoux, 2012) or injecting light, adenosine triphosphate (ATP) or enzymes (Giocondi, Besson, Dosset, Milhiet, \& Le Grimellec, 2007; Johnson, Vasilev, Olsen, \& Hunter, 2014). AFM has also attracted interest as a highly sensitive nano-indenter, opening access to local mechanical properties with nm or nanoNewton resolution (Gavara, 2017; Withers \& Aston, 2006). Grafting the AFM tips with specific ligands further allows measurement of interaction forces between the ligand and binding sites, and allows the molecular mapping of binding sites at the surface of a biological structure (Marszalek \& Dufrêne, 2012; Wei \& van de Ven, 2008). Eventually, the tip itself can be replaced by a colloidal sample to measure interactions with other particles or with surfaces (Beaussart et al., 2014; Gunning \& Morris, 2018). Pioneer applications of the AFM for foodstuff emerged in the late 1990s at the Institute of Food Research (IFR, Norwich, UK), shortly followed by the Ryerson University (Toronto, Canada), the Technion Institute (Haifa, Israel) and others. During the last 20 years, the applications of AFM with food systems have diversified, benefiting from transfers of knowledge from multidisciplinary scientific communities in material sciences, biophysics, physical chemistry, membrane science, microbiology or cell biology. The purpose of this review is therefore to explore the potential of the AFM technique for food systems, through these different approaches. Perspectives and opportunities opened by crossing discipline thinking will specifically be discussed, as a complementary viewpoint to detailed up-to-date or topic-oriented reviews (Ding, Shi, \& Zhong, 2019; Zhong, Finglas, Wang, \& Wang, 2019).

\section{Principle and parts of the atomic force microscope}

Unlike optical or electron microscopes that use a beam to make observation possible, the AFM uses a cantilever, terminated by a tip, to feel the surface of a sample, exactly like a finger can read a surface in Braille (Fig. 1).

Commercial cantilevers are generally made of silicon or silicon nitride electronic chips and protrude from a piece of substrate attachable to the AFM head (Fig. 1 A-D). They come in a wide range of geometries, stiffness values $k$ and reflective coatings. Tips also vary in aspect ratio from whisker nanotubes to colloidal probes, and in radius of curvature for pyramidal tips with sharp to blunted extremities. A laser beam pointed at the free end of the cantilever, reflected to and captured by a quadrant of photodiodes, tracks the spatial position of the cantilever. Ceramic piezos allow accurate measurement of the relative displacements of the AFM probe and/or the sample stage in the XYZ directions with minimal mechanical noise (Fig. 1 E). The AFM technique can be seen as a combination of profilometry and indentation, which accounts for the two main routes of development: imaging and force spectroscopy, developed separately or in combination. As the tip pushes against the sample, the cantilever (with stiffness $k$ ) bends and a deflection (d) is measured on the photodiodes. During raster-scan imaging of the sample, the respective positions of the cantilever and samples are constantly adjusted to keep the loading force $\mathrm{F}=k \mathrm{~d}$ constant (Fig. $1 \mathrm{~F}$ ). Corrections of the AFM tip in the $\mathrm{Z}$ direction during scanning yield the reconstruction image of the sample's topography, as does a profilometer. Alternatively, the AFM tip can be operated to push against the sample up to a trigger force $\mathrm{F}$, then to retract itself a set distance $\mathrm{m}$. Height differences between the retracted positions of the AFM cantilever on each pixel of the explored area XY also yield a reconstructed image of the sample's topography. The major imaging approaches and their application to food systems are introduced in section 3 .
Meanwhile, changes in the deflection of the cantilever during the $\mathrm{Z}$ approach-retract cycle are obtained for each designated XY point of the sample, yielding force-volume information. The measurement and interpretation of individual force curves are known as force spectroscopy and can be compared to the action of a nano-indenter. Mechanical information such as the Young's modulus or stiffness, or interaction forces such as electrostatic or steric repulsion, can be retrieved from the approach (or loading) curve. Meanwhile, adhesion forces or stretching behavior can be retrieved from the retract curve. The main applications to food systems are presented in section 4 along with the description of force curves' segments, while section 5 develops the specific approach of single molecule force spectroscopy. Since AFM implies physical contact between the sample and the moving tip, it is essential that the sample is correctly immobilized onto a substrate. Immobilization methods that keep the native structure of the sample are an important issue in properly using the AFM technique. Furthermore, miniaturization of the XYZ fast raster-scanning movement of the tip imposes dimensional limits to the sample. Better resolution is generally obtained with flat samples that do not require excessive corrections by the feedback loop.

\section{Imaging structures and dynamics at surfaces}

Imaging by raster-scanning of the sample at a constant force is called the "contact mode". Most applications use either direction of the cantilever's main axis or the lateral direction, the latter giving access to friction by simultaneously measuring torsion. The "AC mode" (or intermittent contact mode) requires oscillating the cantilever near its resonant frequency. The loading force is controlled through setting the constant damping of the oscillation when the tip comes in contact with the sample. As for friction in the contact mode, some insight of the mechanical contrast may be measured, as the phase shift will depend on the materials present at the surface of the sample. Detailed discussion of these AFM imaging modes can be found in previous work (Ding et al., 2019; Yang et al., 2007). To decrease the necessary force to finely track samples, "peak force" imaging has been developed from the force-volume approach and reaches frequencies of thousands of force curves/ sec. Recent AFM instruments have significantly increased in speed and spatial resolution (Jones, 2016).

Fig. 2 shows examples of AFM images of ingredient building blocks that could make up a chocolate-chip cake: fat globule and casein micelle from milk (Fig. 2 A and B), chocolate (Fig. 2 C), saccharose (Fig. 2 G), egg yolk (Fig. $2 \mathrm{H}$ ), yeast (Fig. $2 \mathrm{D}$ ), and starch granules and gluten from wheat (Fig. $2 \mathrm{E}$ and F). These images illustrate how AFM contributes to the multiscale investigation of food structures by giving access to micron and sub-micron dimensions. AFM imaging was successfully used to observe structural interactions between glutens' gliadin and glutenin fractions extracted from eggless cakes (Lin, Tay, Yang, Yang, \& Li, 2017).

Among food proteins, gelatin has been studied using AFM as a major texturing agent and a versatile self-organizing protein with heat or hydrolysis (Liu \& Wang, 2011). Many details of collagen fibers are accessible using AFM imaging (Shi et al., 2019a). Globular proteins, such as whey, pea or soy proteins, are typically objects of a few nm diameter. Upon heating, they denature and aggregate into a large range of structures, which can be imaged by simple deposition onto freshly cleaved mica and AFM observation in air or in liquid (Demanèche, Chapel, Monrozier, \& Quiquampoix, 2009; Farrokhi, Badii, Ehsani, \& Hashemi, 2019; Hu et al., 2019; Ikeda \& Morris, 2002; Liu \& Wang, 2011; Touhami \& Dutcher, 2009; Wei, Cheng, \& Huang, 2019; Wei \& Huang, 2020). In binary mixtures, single aggregated units may even be recognized (Adal et al., 2017). Co-aggregates of food protein and polysaccharide, e.g., $\beta$-lactoglobulin with pectin or $\kappa$-carrageenan, or milk with $\kappa$-carrageenan, were also observed with the same approach (Jones, Adamcik, Handschin, Bolisetty, \& Mezzenga, 2010; Olivares, Passeggi, Ferrón, Zorrilla, \& Rubiolo, 2010; Roesch, Cox, Compton, 


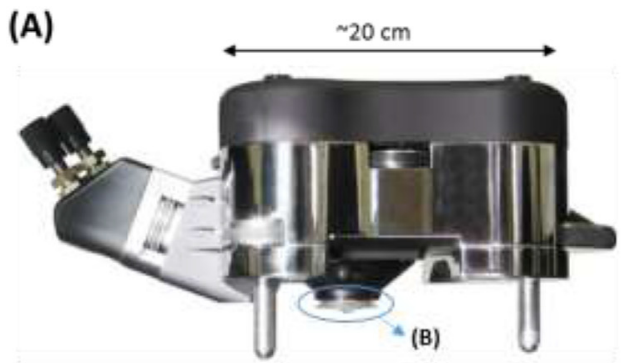

(E)

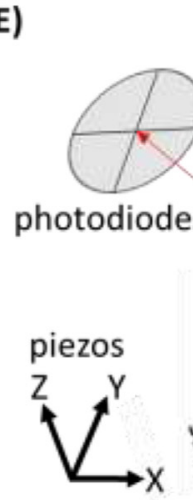

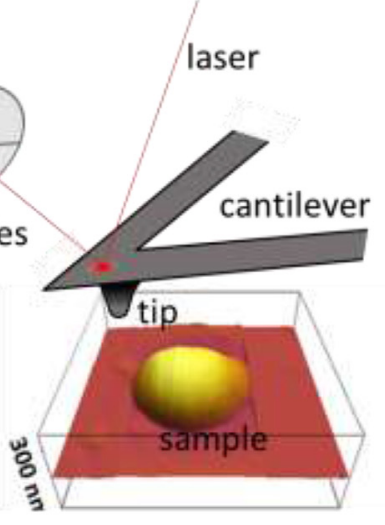

(B)

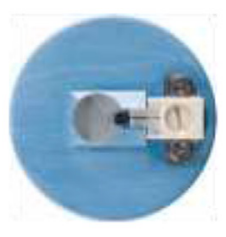

(C)

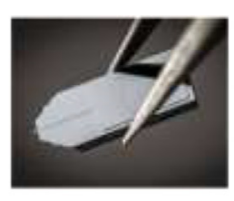

(D)

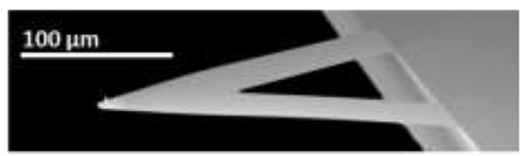

(F)

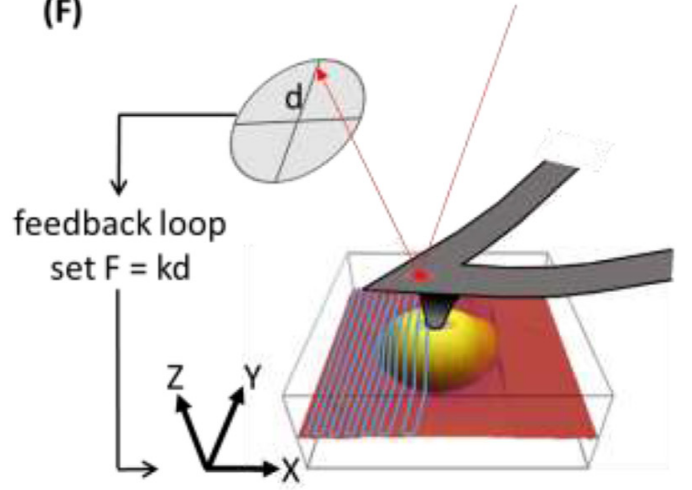

Fig. 1. Equipment and principle of the atomic force microscope (AFM). (A) MFP-3D AFM head; the blue circle indicates the cantilever holder (B), with an AFM probe mounted in front of the quartz optical window. (C) Example of a HQ-300-Au AFM probe (Asylum Research, Oxford Instruments, Santa Barbara, CA, USA) and (D) focus on a triangular MSNL cantilever (Bruker NanoSurfaces, Santa Barbara, CA, USA). (E) Principle of AFM. (For interpretation of the references to color in this figure legend, the reader is referred to the Web version of this article.)
Happek, \& Corredig, 2004). Whey protein superstructures, such as micrometric coacervates of $\alpha$-lactalbumin and lysozyme (Nigen, Gaillard, Croguennec, Madec, \& Bouhallab, 2010) or microbeads of denatured whey protein (Doherty et al., 2010) were also imaged in air, as was fouling of hydrophobic surfaces by bovine serum albumin, $\beta$ lactoglobulin or $\beta$-casein (Pérez-Fuentes, Drummond, Faraudo, \& Bastos-González, 2017). In milk, $80 \%$ of the weight of the proteins are found in the casein micelles, which are 150-200 nm hydrogel particles of the $\kappa-, \alpha_{\mathrm{s} 1^{-}}, \alpha_{\mathrm{s} 2}$-and $\beta$-caseins bound by hydrophobic interactions and calcium phosphate nanogranules. AFM was used to follow the structure resulting from the layer-by-layer deposition of individual caseins onto polyelectrolyte surfaces, to cast light on the possible pathways for the casein micelle assembly (Nagy, Váró, \& Szalontai, 2012). The casein micelles may also be spread onto freshly cleaved mica but only closepacking will prevent dissociation at the interface (Ouanezar, unpublished observation). With this approach, the effect of pressure, fouling or enzymatic coagulation on the morphology of casein micelles layers could be visualized on dessicated concentrated samples spread onto mica, glass or silicon nitride (Freitas et al., 2019; Gebhardt, Doster, Friedrich, \& Kulozik, 2006, 2011; Regnault, Thiebaud, Dumay, \& Cheftel, 2004). To identify individual casein micelles, they need more specialized immobilization, e.g., on freshly cleaved graphite (Helstad, Rayner, van Vliet, Paulsson, \& Dejmek, 2007), glass (Freitas et al., 2019), self-assembled monolayers (Christensen, Rasmussen, \& Simonsen, 2015; Ouanezar et al., 2012; Silva, Bahri, Guyomarc'h, Beaucher, \& Gaucheron, 2015; Uricanu, Duits, \& Mellema, 2004, Fig. 2 B) or substrates coated with casein-specific monoclonal antibody (Bahri et al., 2017, 2018). AFM imaging then provides details on their dimensions and roughness (Christensen et al., 2015; Ouanezar et al., 2012). Finally, the casein micelles may be parted into $\sim 20 \mathrm{~nm}$ particles called caseinates, which can be used as a carrier for curcumin or thymol, and observed using AFM after deposition onto cleaved mica (Pan, Chen, Davidson, \& Zhong, 2014). Additional advanced uses of AFM imaging exist that unravel structural features of food-related
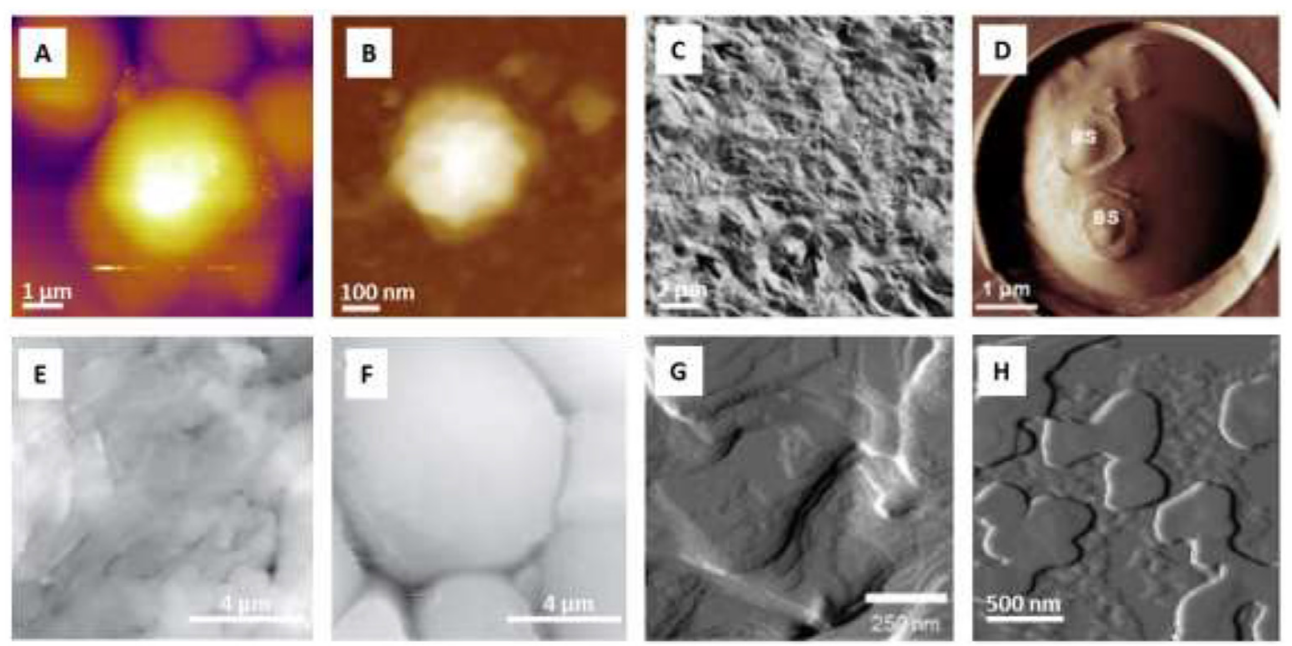

Fig. 2. Possible building blocks of a baked cake as imaged using AFM. (A) Native milk fat globules of unprocessed milk (Guyomarc'h, unpublished); (B) casein micelles from skim milk (Ouanezar et al., 2012); (C) freshly tempered chocolate (Rousseau \& Sonwai, 2008); (D) Saccharomyces cerevisae entrapped in a pore of a polycarbonate porous membrane, with bud scars (BS) on its surface (Pillet et al., 2014); (E) gluten and (F) starch from wheat (Chichti, George, Delenne, Radjai, \& Lullien-Pellerin, 2013); (G) saccharose crystals (Middendorf, Bindrich, Mischnick, Franke, \& Heinz, 2018) and (H) lipoprotein from egg yolk spread onto a mica surface (Dauphas et al., 2007a). 
proteins, e.g., periodicity, lysis or connectivity (Shi, He, Ding, Wang, \& Zhong, 2019c, 2019b; Yang et al., 2007).

The milk fat globule is an even more complex milk colloidal assembly, consisting of an oil droplet enveloped by a trilayer polar lipid membrane decorated with embedded and peripheral membrane proteins and a glycocalyx (Lopez, 2011). AFM images nevertheless succeeded in showing the damage of the native milk fat globules with processing (Balasuriya, Ong, Gras, \& Dagastine, 2012) or change in rugosity upon homogenization (Obeid et al., 2019a). For egg yolk's low density lipoprotein (LDL), AFM imaging of Langmuir-Blodgett films was used to investigate structural interactions between polar lipids and apoproteins (Dauphas et al., 2007b, 2007a; Martinet, Saulnier, Beaumal, Courthaudon, \& Anton, 2003). In microbiology, the surface of food-grade or of food-poisoning microorganisms offers a large field of applications for AFM investigation, as previously reviewed (Dorobantu, Goss, \& Burrell, 2012; Liu \& Wang, 2011; Liu \& Yang, 2019). The resolution of AFM imaging and the absence of fixation pretreatment allows access to stress-induced changes or lysis of the cell wall (Derde et al., 2014; Dorobantu et al., 2012; Formosa \& Dague, 2015; Liu \& Wang, 2011). More particularly, fine structures such as the S-layer are also visible using AFM imaging (Dupres, Alsteens, Pauwels, \& Dufrene, 2009). Images can be further completed by the nanoscale mapping of the dielectrical constants of bacteria using electrostatic AFM (EstebanFerrer, Edwards, Fumagalli, Juárez, \& Gomila, 2014). Applications of AFM for food packaging are out of the scope of this review and can be found elsewhere (Marinello, La Storia, Mauriello, \& Passeri, 2019).

AFM imaging has also been used to image polysaccharide structures, alone or in mixtures. Applications to immobilized fractured starch granules or spherulites with crystalline structures, amylose, amylopectin fibers or gelatinized starch deposited on mica then dessicated, have been reviewed (Murrieta-Pazos et al., 2012; Wang \& Nie, 2019; Zhu, 2017). Carrageenans, locust bean gum, guar gum, gellan gum, gum arabic, xanthan or pectin fibrous structures were also investigated (Funami, 2010; Gunning \& Morris, 2018; Ikeda, Funami, \& Zhang, 2005; Liu \& Wang, 2011; Wang \& Somasundaran, 2007). Crystalline structures of lactose (Dincer, Ogden, \& Parkinson, 2014; Gao et al., 2017; Perkins et al., 2007), of saccharose (Masterson \& Cao, 2008; Middendorf et al., 2016, 2018) or of calcium phosphate assemblies ( $\mathrm{Li}$, Wang, \& Putnis, 2018; Wang, Lu, Xu, \& Zhang, 2011; Čadež et al., 2018) are also accessible using AFM imaging.

Since it does not need fixed samples, AFM imaging is especially suited to monitor crystal growth and to measure changes in periodic dimensions, stack height or growth directions at the nanoscale (Gao et al., 2017, Fig. 3 A). A major application of AFM to follow crystal development in foodstuff was that of the formation fat bloom in chocolate (Hodge \& Rousseau, 2002; Rousseau \& Sonwai, 2008; Smith \& Dahlman, 2005, Fig. 3 B). Dynamics of food interfaces of emulsion and foams were obtained using AFM imaging of Langmuir films of milk proteins, transferred and immobilized onto freshly cleaved mica at various stages of their disorganization by a competing detergent (Mackie, Gunning, Wilde, \& Morris, 2000, 1999; Morris, 2004; Woodward, Gunning, Mackie, Wilde, \& Morris, 2009). Using these observations, the IFR group was able to propose a generic pathway for the displacement of an initial protein network at the air/water or oil/ water interfaces by a more surface-active molecule (Fig. 3 D). Recent technical advances such as the immersion of AFM probes directly in contact with oil/water interfaces (Costa, Li-Destri, Thomson, Konovalov, \& Pontoni, 2016, 2017) or possibly with the air/water interface of a Langmuir trough (Frédéric Dubreuil, personal communication) open new approaches for the direct AFM observation of dynamic interface events relevant to food emulsion or foams.

In microbiology or cell biology, applications of time-resolved AFM imaging of the formation of thin protein films on surfaces, sometimes showing complex two-dimensional paracrystalline organizations (TocaHerrera, Moreno-Flores, Friedmann, Pum, \& Sleytr, 2004) and/or highspeed dynamics (Uchihashi \& Scheuring, 2018) can be measured. AFM has thus allowed detailed observation of protein organization on bacterial surfaces (Dufrene, 2004; Dupres, Alsteens, Andre, \& Dufrene, 2010) and in membranes (Fotiadis, 2012). Organization and dynamics of myosin displacement along actin filaments is another achievement of high-speed AFM (Ando, Uchihashi, \& Kodera, 2013), which could be of interest for meat/muscle studies. In food systems, the fibrillation dynamics of, e.g., soy or whey proteins have been monitored using AFM (Bolisetty, Adamcik, \& Mezzenga, 2011; Gosal, Clark, \& Ross-Murphy, 2004; Tang, Wang, \& Huang, 2012).

AFM imaging in biology has allowed significant insight into the structure and dynamics of lipid membranes. Langmuir-Blodgett supported lipid monolayers are generally prepared on mica then imaged in air. Closer to natural membranes, supported lipid bilayers are deposited on mica either using the Langmuir-Schaeffer technique or vesicle fusion, then imaged in buffer. The morphology of binary membranes with ordered and disordered phases, ionic or temperature effects, as well as protein interaction with lipid membranes can all be explored dynamically on supported bilayers using AFM time-resolved imaging (Alessandrini \& Facci, 2011, 2014; Giocondi et al., 2010; Morandat, Azouzi, Beauvais, Mastouri, \& El Kirat, 2013). In food systems, lipid membranes are found in plant or animal tissues, bacterial wall, extracellular vesicles including exosomes and the milk fat globules. The often complex polar lipid compositions of natural extracts such as milk (Gallier, Gragson, Jiménez-Flores, \& Everett, 2010; Guyomarc'h et al., 2014, 2017), rapeseed or salmon fat (Jacquot et al., 2014) makes AFM a preferred technique to better understand membrane structures at the nanoscale. The formation or melting of the milk sphingomyelin-rich domains in bilayer models of the milk fat globule membrane have been imaged using AFM upon cooling or heating (Et-Thakafy, Guyomarc'h, \& Lopez, 2019; Guyomarc'h et al., 2014; Murthy et al., 2016a). The adsorption of caseins onto membranes of milk polar lipids is visible on dessicated monolayers (Gallier et al., 2010) and is dynamically followed on hydrated bilayers where casein micelles could only adsorb on disordered and electrically neutral polar lipid phases (CrespoVillanueva et al., 2018; Obeid et al., 2019b, Fig. 3 E). Langmuir-Blodgett monolayers of mixed milk polar lipids and proteins were imaged with AFM to investigate organizations at the surface of food oil/water emulsions (Berton-Carabin, Genot, Gaillard, Guibert, \& Ropers, 2013; Lucero Caro, Rodríguez Niño, \& Rodríguez Patino, 2009). Time-resolved AFM images are helpful to observe the insertion of proteases or lipases into thin food protein films or lipid monolayers, respectively, as well as the effects of digestion on the structure of the films (Bourlieu et al., 2016; Maldonado-Valderrama, Gunning, Wilde, \& Morris, 2010, Fig. 3 C).

\section{Nanomechanics of individual building blocks to cast light on texture of complex food systems}

In addition to acting as a profilometer, the AFM can also operate as a nanoscale indenter and therefore combine structural with mechanical information on every pixel of a force map. Fig. 4 shows two examples of force curves obtained by indenting a supported lipid bilayer or a bacterium and shows typical information that can be obtained from them.

At the start of the force spectroscopy cycle, the AFM tip is at rest, away from the sample. Deflection, hence the force, is therefore zero. As the tip moves towards the sample, the zero force baseline (1) is recorded up to the contact point (2) where the force starts to rise. When soft samples are investigated, the force curve deviates from a linear hardcontact response (Butt, Cappella, \& Kappl, 2005; Heinz \& Hoh, 1999). The segment (3) is then showing indentation of the tip into the soft sample and can be fitted with appropriate models to obtain elastic properties such as the Young's modulus. However if repulsion occurs between tip and a soft sample upon approach, e.g., in air or in a low ionic strength liquid, determination of the contact point may be somewhat tricky. However, repulsion is negligible in liquid environments especially with saline conditions, typically physiological buffers. 

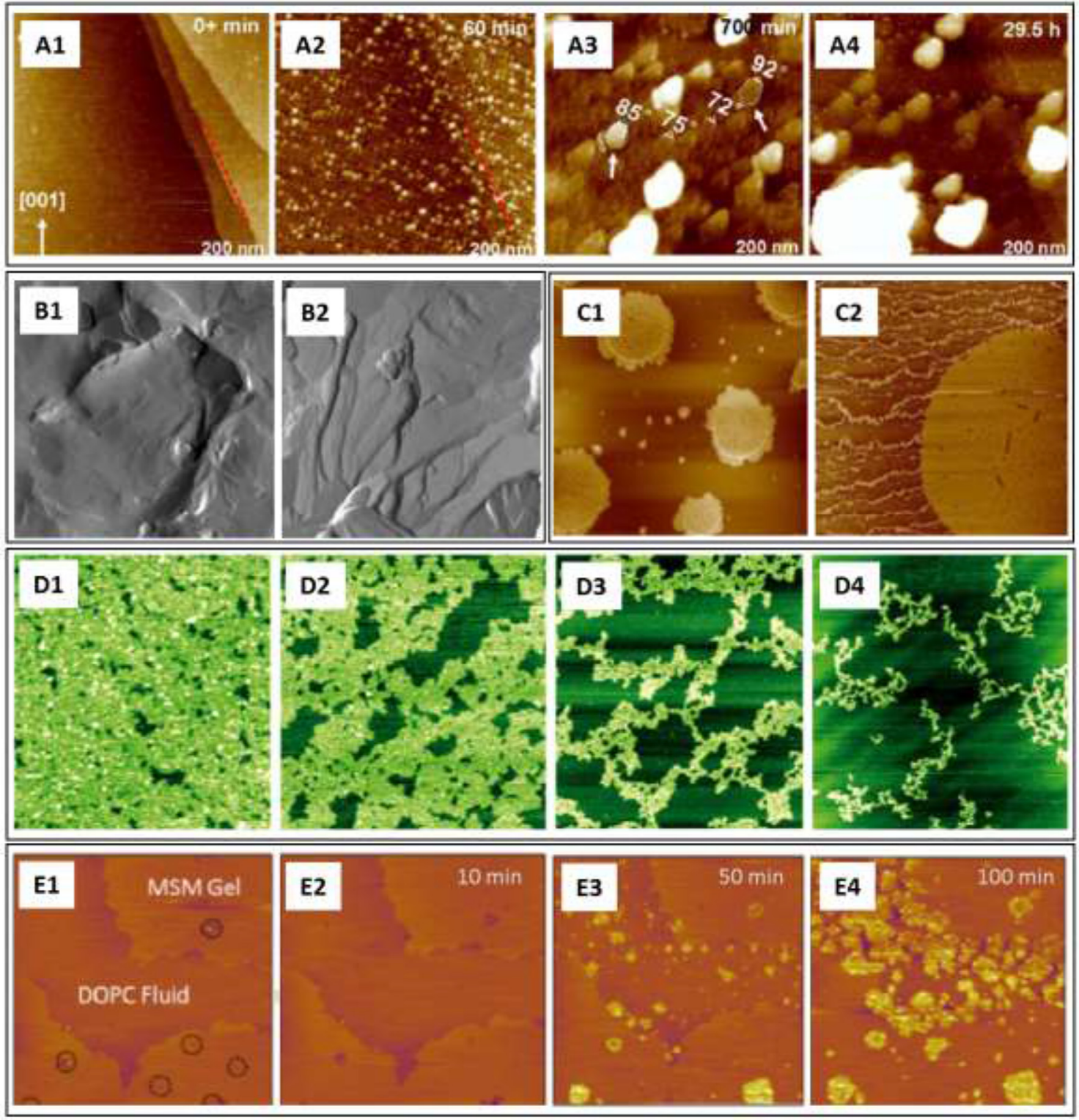

Fig. 3. Monitoring dynamic processes using AFM imaging. (A1-4) Formation of calcium phosphate hydroxyapatite crystals and supra-assemblies (Li, Wang, Zhang, Putnis, \& Putnis, 2016, 2018). (B1-2) Formation of fat crystals in tempered chocolate after 4 wk of storage at $25{ }^{\circ} \mathrm{C}$ (scan size: $5 \times 5 \mu \mathrm{m}^{2}$ (Rousseau \& Sonwai, 2008)). (C1-2) Insertion of recombinant dog gastric lipase onto a Langmuir film of milk polar lipid extract (scan size: $2.5 \times 2.5 \mu m^{2}$ (Bourlieu et al., 2016)). (D1-4) Displacement of a spread $\beta$-lactoglobulin protein film formed at an air/water interface (light color network) by the surfactant Tween 20 (dark areas; scan size: $1 \times 1 \mu \mathrm{m}^{2} ; 1.6 \times 1.6 \mu \mathrm{m}^{2} ; 3.2 \times 3.2 \mu \mathrm{m}^{2}$ and $10 \times 10 \mu \mathrm{m}^{2}$ from left to right (Morris, 2004)). (E1-4) Adsorption of casein micelles onto binary supported lipid bilayers of dioleoylphosphatidylcholine (DOPC) in the disordered (fluid) phase and milk sphingomyelin (MSM) in the gel phase (scan size: $5 \times 5 \mu \mathrm{m}^{2}$ (Obeid et al., 2019b). (For interpretation of the references to color in this figure legend, the reader is referred to the Web version of this article.)

In some research, repulsion is measured between the hard tip and hard substrate by varying the liquid environment and observing deviation from the hard-contact response (see section 4.3). Upon increasing the loading force, the AFM tip sometimes breaks through the sample, which is shown on the approach curve as a sharp move at constant force (4. When the AFM tip pulls away from sample, negative peaks (5) sometimes occur that are evidence of tip-sample adhesion. The shape of the peak(s) indicates the nature of adhesion, either capillary (in air), mechanical adhesion, polymer extension or multiple binding events (Heinz \& Hoh, 1999). A combination of these is possible. The AFM tip can be set to pull away so as to fully detach from the sample and go back to rest ๑. The approach-retract cycle can then start again.

\subsection{Elasticity and stiffness}

In food systems, AFM has been used to investigate the mechanical properties of small objects or to show mechanical heterogeneities at the nanoscale that are otherwise impossible to measure with conventional nano-indenters. With minimal syneresis, evaluation of the Young's modulus of gelatin gels using AFM at the $\mu \mathrm{m}$ scale were in good agreement with measurement of the elastic moduli by macroscale rheometry (Uricanu, Duits, Nelissen, Bennink, \& Mellema, 2003). In this pioneer study, the measurement of local structural features, such as fibrils, was linked with the bulk mechanics of the heterogeneous sample. AFM has also been used to evaluate the Young's modulus of small objects such as the milk's casein micelles (Bahri et al., 2017, 2018; Helstad et al., 2007; Uricanu et al., 2004). When the tip is properly positioned at the apex of the micelles, values of hundreds of $\mathrm{kPa}$ order 


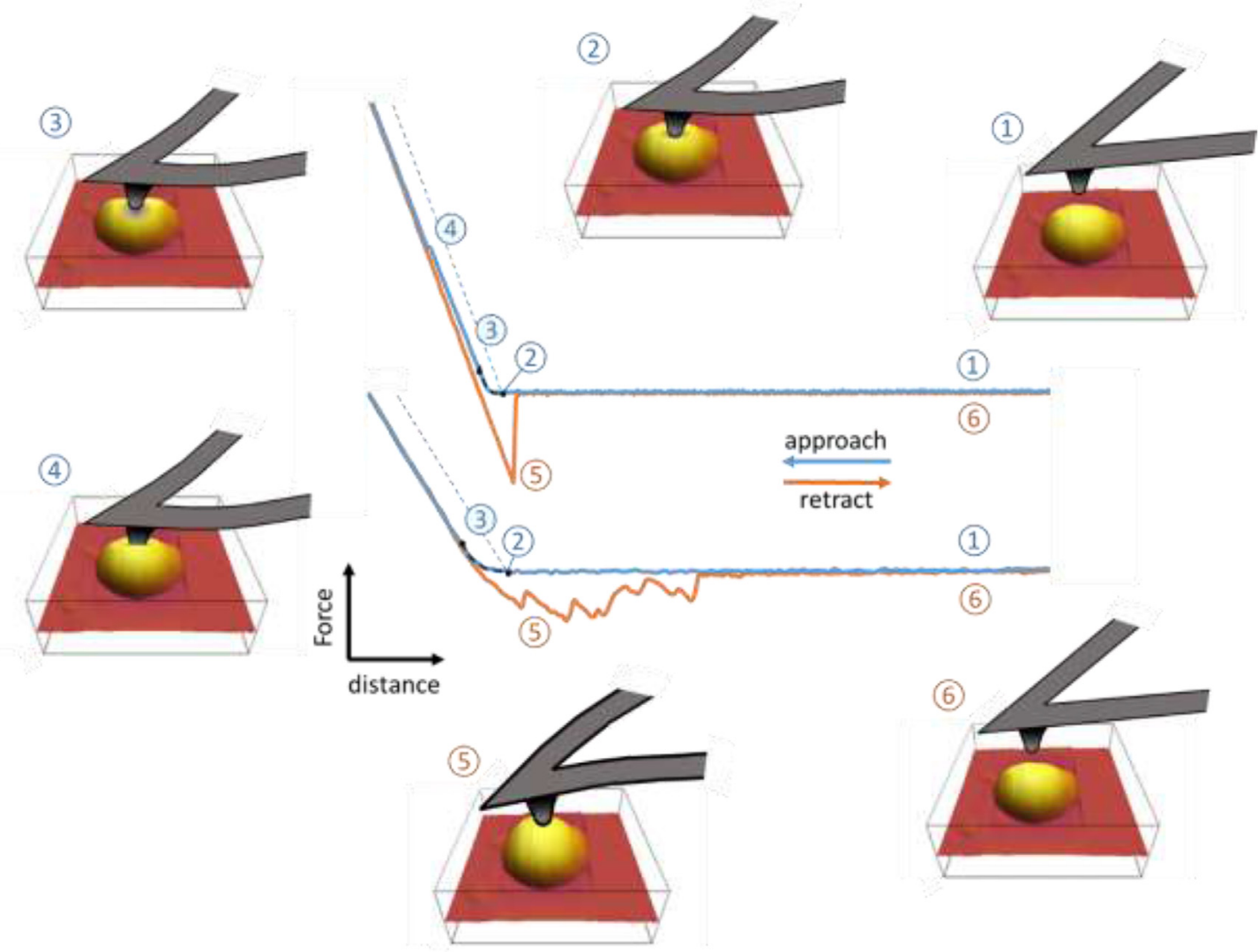

Fig. 4. General view of the mechanical information resulting from AFM force spectroscopy measurements. The figure shows two examples of force curves resulting from approach (blue curves) and retract (orange curves) cycles. The blue dashed segments show the hard contact reference of the approach curves. The upper curves are from indentation and breakthrough of a supported lipid bilayer (Murthy et al., 2016a) and the lower curves are from indentation of dairy propionibacteria and pulling of capsular exopolysaccharides (Guyomarc'h et al., in preparation). Numbers (1), (2), (3), (4), (5) and ๑ refer to the corresponding relative positions of the sample and cantilever during the force spectroscopy cycle. The black dashed line on the approach curve indicates the segment (3) where elastic behavior is measured. (For interpretation of the references to color in this figure legend, the reader is referred to the Web version of this article.)

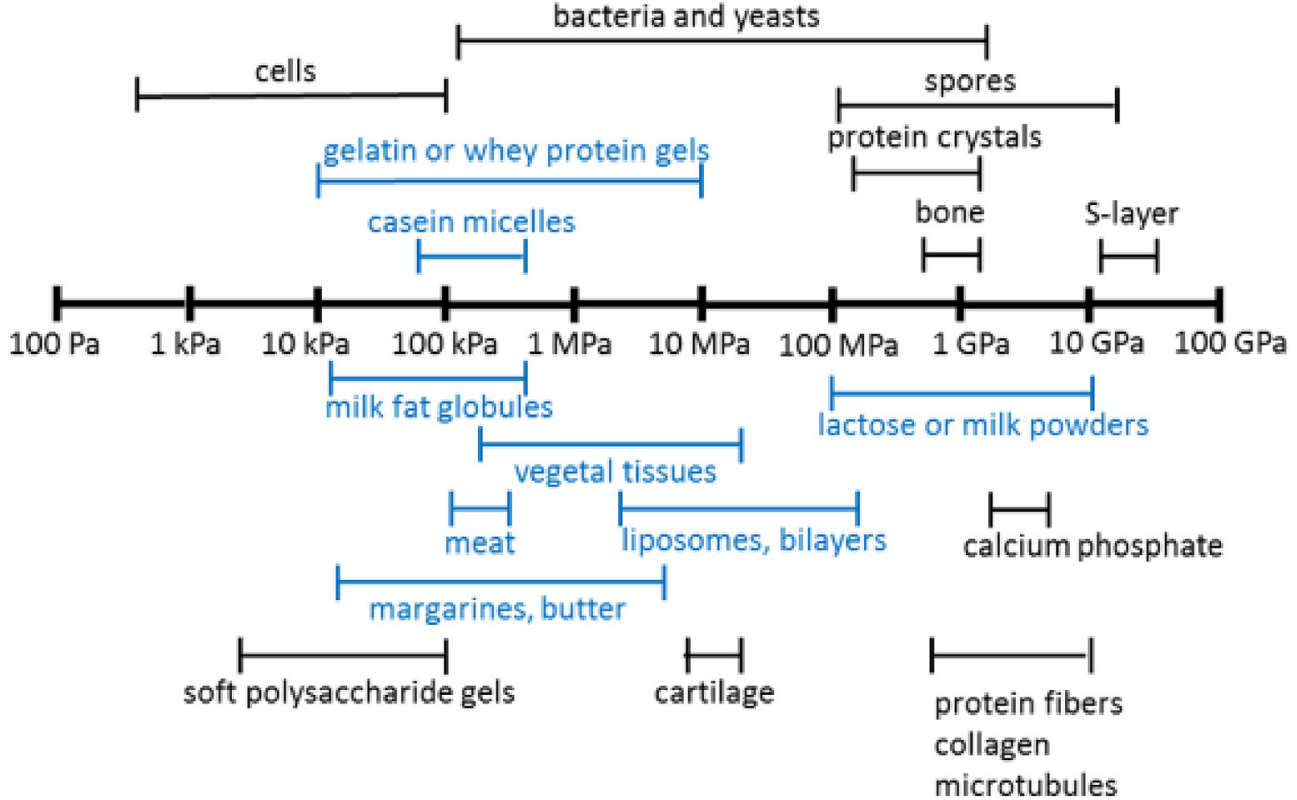

Fig. 5. Typical ranges of Young's modulus values reported for biological samples, including food-related samples (in blue). The figure is adapted from an application note by JPK Instruments (www.jpk.com) with data added from work by Arfsten et al. (2010), Bahri et al. (2017, 2018), Balasuriya et al. (2012), Burgain et al. (2016), Cárdenas-Pérez et al. (2019), Costa et al. (2012)*, Et-Thakafy et al. (2017), Fang, Kang, Hong, and Wu (2012), Galus and Kadzińska (2016)*, Helstad et al. (2007), Kasas, Stupar, and Dietler (2018), Kloek, Van Vliet, and Walstra (2005)*, Kurland, Drira, and Yadavalli (2012), Lam and Ikeda (2017)*, Masterson and Cao (2008), Nowak, Markowski, and Daszkiewicz (2015)*, Perkins et al. (2007), Uricanu et al. (2004), Vithanage, Grimson, and Smith (2009)* and Xu et al. (1996). References with a star * did not use AFM. (For interpretation of the references to color in this figure legend, the reader is referred to the Web version of this article.) of magnitude were reported, coherent with protein hydrogels (Fig. 5). For comparison, alginate hydrogel beads are about 10 times softer (Lekka, Sainz-Serp, Kulik, \& Wandrey, 2004).

The Young's modulus of casein micelles increases with covalent reticulation (Bahri, Martin, Gergely, Marchesseau, \& Chevalier-Lucia, 2018) and with temperature (Uricanu et al., 2004), as expected. However, it does not significantly change with acidification, in spite of the sol/gel transition of milk. This indicates that the bulk elasticity of 


\section{Untreated skim milk: " contact " angle $~ 35-45^{\circ}$}

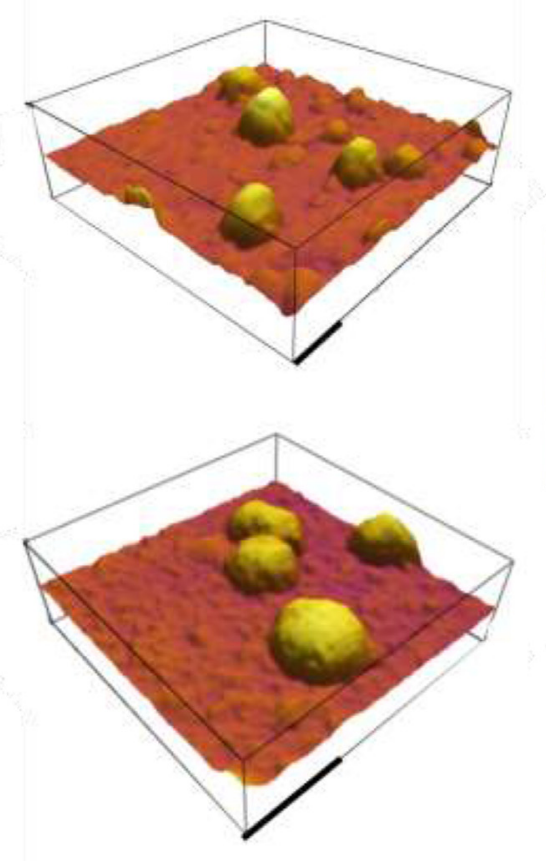

Heat-treated skim milk " contact $"$ angle $\sim 45-55^{\circ}$
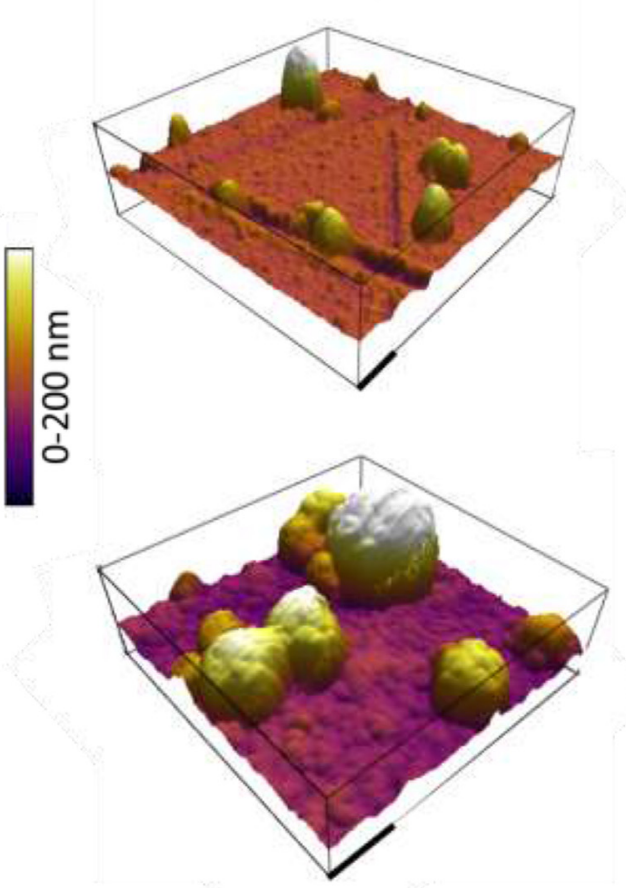

Fig. 6. AFM topographical images of casein micelles, immobilized onto gold substrate using carbodiimide chemistry and imaged in air. Left: untreated skim milk; right: heat-treated $\left(80{ }^{\circ} \mathrm{C} /\right.$ 20 min) skim milk. The "contact" angle was calculated using AFM measurements of the basal width and maximum height of individual micelles (Helstad et al., 2007). The scale bars are $200 \mathrm{~nm}$. (For interpretation of the references to color in this figure legend, the reader is referred to the Web version of this article.) acid milk gels is determined by the stiffness of the inter-micelle links rather than by the intra-micelle links (Uricanu et al., 2004). Instead of force measurements, AFM imaging may help predict the Young's modulus of polymer particles using their deformation upon adsorption onto a surface (Evangelopoulos, Glynos, Madani-Grasset, \& Koutsos, 2012). Similarly, the calculation of a "contact" angle is used to evaluate stiffness changes of casein micelles as a consequence of chemical crosslinking, demineralization, acidification (Helstad et al., 2007; Silva et al., 2015) or heating in the presence of whey proteins (Micleusanu et al., unpublished results; Fig. 6). Upon heating, the stiffness of eggwhite ovalbumin films measured using AFM force spectroscopy decreased while adhesion increased as a result of denaturation and gelation (Najbar, Considine, \& Drummond, 2003).

The use of AFM indentation at liquid/liquid or liquid/air interfaces to measure the stiffness of sessile liquid droplets has been explored but is still difficult to implement (Costa, Li-Destri, Pontoni, Konovalov, \& Thomson, 2017; Munz \& Mills, 2014; Wang et al., 2016). Similarly, calculation of the stiffness or the Young's modulus of filled microcapsules (Berry, Mettu, \& Dagastine, 2017; Sarrazin et al., 2016; Tan et al., 2016) or phospholipid-shelled microbubbles (Buchner Santos, Morris, Glynos, Sboros, \& Koutsos, 2012; Grant et al., 2012) requires further mathematical developments. These approaches have only been used limitedly with food systems, e.g., edible $\sim 1$ MPa microcapsules of pea proteins (Ye et al., 2016) or emulsion droplets (Wackerbarth et al., 2009). As a macrovesicle enveloped with a plasmatic membrane, the Young's modulus of milk fat globules was found to increase from tens to hundreds of $\mathrm{kPa}$ when the milk was homogenized, because of adsorbed casein micelles (Balasuriya et al., 2012).

Indentation of $\sim 100 \mathrm{~nm}$ diameter liposomes by an AFM tip is sensitive enough to show that polar lipids in the fluid phase yield softer liposomes than those made with polar lipids in the gel phase (EtThakafy et al., 2017). Liposomes in the liquid-ordered phase, i.e., polar lipids with cholesterol, were in between these two extremes (Liang, Mao, \& Ng, 2004; Takechi-Haraya et al., 2016). In general, slightly higher moduli values were obtained from measurements taken on supported lipid bilayers than on liposomes, probably because of compression against the underlying substrate (Das, Sheikh, Olmsted, \& Connell, 2010; Et-Thakafy et al., 2017; Picas, Rico, \& Scheuring, 2012). Liposomes of milk sphingomyelin, involving a naturally complex composition of saturated and unsaturated molecules of varying chain lengths, show lower Young' modulus values than liposomes of single or binary composition (Et-Thakafy, Delorme, Guyomarc'h, \& Lopez, 2018). Higher order polar lipid organization of simple liposomes may account for their relatively high Young's modulus values compared to those of complex biological samples (respectively tens of MPa $v s$ hundreds of $\mathrm{kPa}-$ Fig. 5). Spherulites of hydrogenated canola oil/sunflower oil triacylglycerides showed Young's modulus values of a few MPa (Yoshikawa et al., 2017). Dry food powders, such as lactose, saccharose or milk casein micelles powders, showed higher modulus values in the range of 0.1-10 GPa (Burgain, Scher, Petit, Francius, \& Gaiani, 2016; Masterson \& Cao, 2008; Perkins et al., 2007).

Readers interested in the applications of AFM to measure nanomechanical properties of vegetable, fruit or meat tissues are encouraged to peruse recent reviews (Cárdenas-Pérez et al., 2019; Posé et al., 2019). Bacteria and yeasts, including food-grade lactic acid bacteria or baker's yeast Saccharomyces cerevisiae, have also been the subject of many mechanical evaluations using AFM indentation (Arfsten, Leupold, Bradtmöller, Kampen, \& Kwade, 2010; Bui, Kim, \& Choi, 2008; SchaerZammaretti \& Ubbink, 2003; Touhami, Nysten, \& Dufrene, 2003). The Young's modulus value of thin-layered recrystallized S-layer proteins of Propionibacterium freudenreichii, a starter for Swiss-type cheeses, was found to decrease with heating or acidification, both relevant in cheesemaking and digestion (de sa Peixoto et al., 2015).

\subsection{Micro-rheology, drying kinetics, and interfacial tension}

The resonant AFM cantilever or tip can be used as a micro- or nanoscale geometry for mechanical evaluation of samples. Cantilevers or nanowire tips can be immersed in different liquids, including sugar or salt solutions or milk, and be used as viscosity sensors in low viscosity media (Ahmed, Nino, \& Moy, 2001; Lemaire, Heinisch, Caillard, Jakoby, \& Dufour, 2013; Papi, Arcovito, De Spirito, Vassalli, \& Tiribilli, 

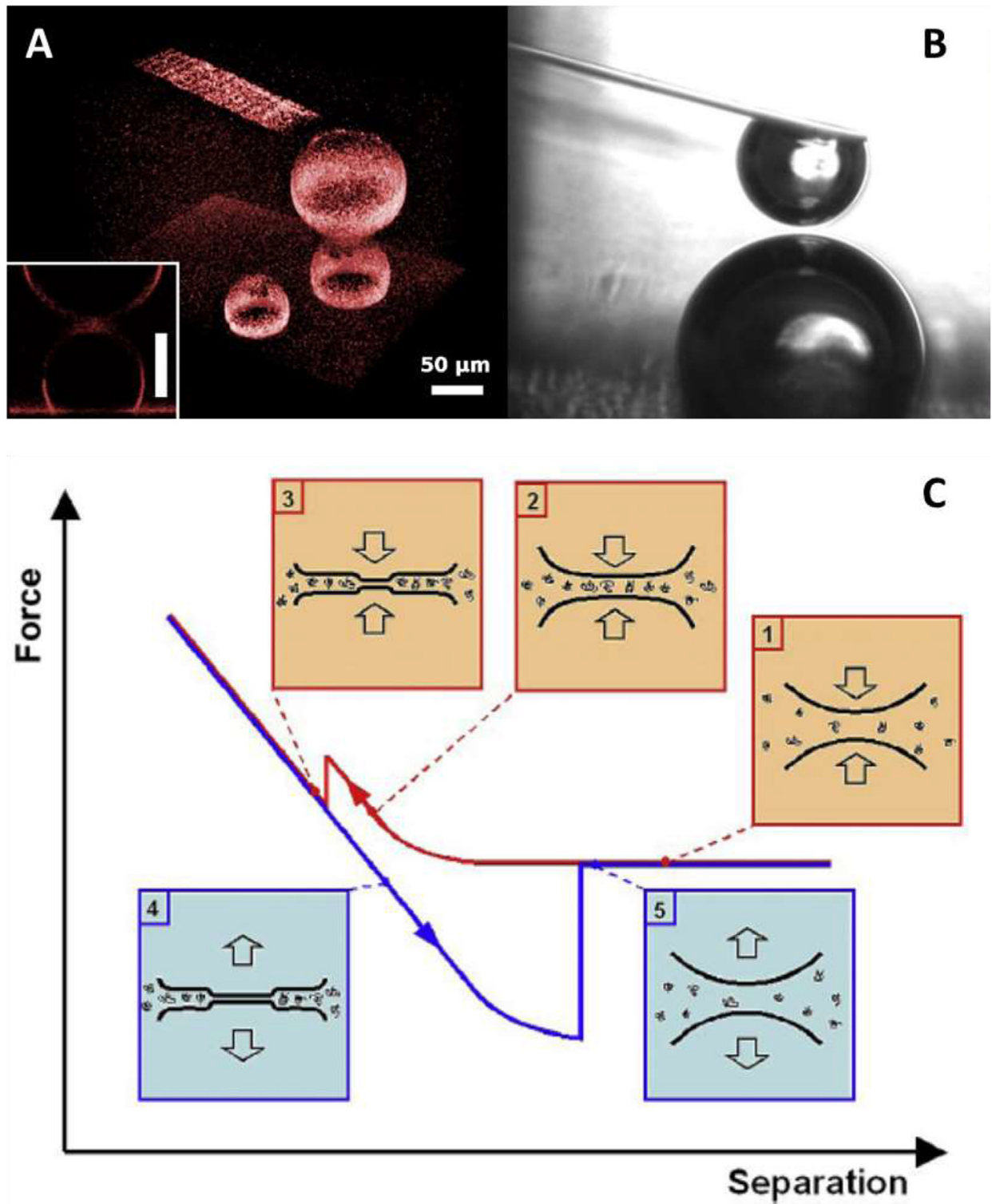

Fig. 7. Experimental set-up to investigate colloidal interaction between deformable particles. (A) 3-Dimensional reconstruction obtained using laser scanning confocal microscopy, taken in situ in the AFM, just prior to a colloid-colloid interaction measurement imaged in (B) (Tabor et al., 2011, 2012). The inset shows a vertical plane through (A). (C) Example of a dropletdroplet interaction force curve as measured using AFM (Gunning \& Morris, 2018). Upon approach, as the droplets are far away they do not interact (1), but start to deform at closer distance to form a thin liquid film (2) up to the point when interfaces may jump into contact (3. Upon retraction, the droplets keep in contact (4) until the pulling force counter-balances the suction effect of the thin film and detach (5) to return their initial shape.
2006). Using a similar approach, AFM cantilevers can monitor clotting of blood (Feller, Kellermayer, \& Kiss, 2014), which suggests it might also be applied to milk clotting. The extremity of the oscillating AFM tip, when put in contact with a nL sessile droplet, can stress the meniscus laterally to monitor viscoelastic properties (Lee et al., 2016; Li, Chiu, Ortiz-Young, \& Riedo, 2014). Combined quartz crystal microbalance (QCM-D) measurements and AFM can be used to calculate thickness, density, viscosity and elasticity changes of a thin serum albumin film with dehydration-rehydration cycles (Lubarsky, Davidson, \& Bradley, 2007). The tip-less AFM cantilever was coated with the protein film and oscillated in nitrogen atmospheres with varying humidity. Kinetics and thermic effects of the evaporation of water droplets may be monitored using AFM (Bonaccurso \& Butt, 2005; Golovko et al., 2008; Haschke, Lautenschlager, Wiechert, Bonaccurso, \& Butt, 2005). In this approach, a droplet is placed at the top of an AFM cantilever that will consequently bend due to the surface tension of the liquid, the Laplace pressure inside the droplet, interfacial stress at the solid-liquid boundary and evaporative cooling. Changes in the deflection of the cantilever show different evaporation behaviors depending on the cantilever's surface.

The use of AFM to measure interfacial tension of droplets or bubbles has also been reported. Using the theory by Attard and Miklavcic
(2001), Filip, Uricanu, Duits, Agterof, and Mellema (2005) used force curves measured on droplets of a water-in-oil emulsion using $5 \mu \mathrm{m}$ colloidal tips to calculate stiffness values that matched well with interfacial tensions measured by other techniques. Needle tips could alternatively be used to measure the interfacial tensions of oil droplets immersed in an aqueous phase or of bubbles produced in water by cavitation (McGuiggan \& Wallace, 2006; Uddin, Tan, \& Dagastine, 2011). The use of standard pyramidal AFM tips introduces geometrical complications in the deformation of the interface but interfacial tension may be able to be determined with standard AFM set-ups in the future (Costa et al., 2016, 2017).

\subsection{Interactions between hard surfaces}

Analogous to a surface force apparatus (SFA), the AFM colloidal probe technique has been developed to measure interaction forces between a plane and the near-plane cap of a micrometer-large particle attached at the end of a tip-less cantilever. Measurements can be made in liquid and the retrieved force curves obey Derjaguin-Landau-VerweyOverbeek (DLVO) predictions (Butt, 1991; Ducker, Senden, \& Pashley, 1991, 1992). Experiments generally involve careful positioning of the AFM probe at a constant altitude with respect to the surface, established 
using conditions of minimal repulsion, i.e., when identification of the contact point is clear, followed by modification of the ionic strength (Butt, 1991; Meagher \& Griesser, 2002). Others align the hard-contact segment of the different force curves obtained with varied environmental conditions with the same tip/substrate couple (Finessi et al., 2011). Interaction forces were measured this way between facing layers of biological materials attached to the colloidal probe and the surface, such as two lactoferrin, apoferritin or bovine serum albumin (BSA) layers with different conditions of $\mathrm{pH}$ or ionic strength (Meagher \& Griesser, 2002; Valle-Delgado et al., 2004, 2005, 2006). More recently, a new set-up was proposed where interaction forces were measured between two coated spheres for symmetrical geometries and lesser contamination (Finessi et al., 2011; Sinha et al., 2012). This system has been successfully developed to measure interaction forces between monolayers of oppositely charged albumin and lysozyme with various conditions of $\mathrm{pH}$ and ionic strength (Singh, Bremmell, Griesser, \& Kingshott, 2015). The interaction forces between individual carboxylated colloidal particles, measured using AFM and interpreted with the DLVO theory, predicted well their aggregation rate in bulk (RuizCabello et al., 2013), which could find applications with other aggregating food colloids such as the casein micelles. Application on soft samples also exist, e.g., to measure electrostatic repulsion at different $\mathrm{pH}$ between a silicon nitride tip and bacteria with distinct capsule compositions (Camesano \& Logan, 2000).

\subsection{Interactions between pairs of bubble/bubble, droplet/droplet or droplet/bubble}

Pioneer development of both mathematical models (Dagastine, Stevens, Chan, \& Grieser, 2004; Tabor, Grieser, Dagastine, \& Chan, 2012, 2011; Wang et al., 2015) and technical set-ups (Dagastine, 2006; Gunning, Mackie, Wilde, \& Morris, 2004, Fig. 7A and B) by the IFR Norwich and the University of Melbourne groups have opened a field of research for the AFM investigation of interactions between deformable bodies such as droplets or bubbles. This is of prime interest for food applications like emulsions or foams.

Forces acting at the surface of droplets or bubbles are better evaluated between pairs of objects, one attached to the end of a (tipless) cantilever and the other adsorbed onto a flat surface, rather than on a single object indented using an AFM probe (Gunning \& Morris, 2018, Fig. 7 C). Upon approach of the facing objects, positive deflection of the cantilever is observed because of resultant long range repulsion, e.g., electrostatic repulsion, and hydrodynamic forces exerted by the squeezed material/solvent between the two objects, e.g., disjoining pressure of solvent or steric repulsion of surfactants (Fig. 7 C2). As load increases, the Laplace pressure of the bubble or droplet, defining nonpenetrable thickness, causes their deformation normal to the applied force, with possible wavy features forming at the contact area (Gunning et al., 2004; Wang et al., 2015). Depending on the bulk composition and the fluxes of the thin film between the two objects, local depletion in, e.g., bulk material sometimes induces a strong attraction, visible as a jump-in event (Gunning \& Morris, 2018; Tabor et al., 2012, Fig. 7 C3). As they are pulled apart, capillary-like adhesion is visible due to the suction effect exerted by the deformed objects (Wang et al., 2015, Fig. 7 C4). Deformability of objects requires complex mathematical treatment of the force curve information but yields highly sensitive measurements as a consequence of the increased contact area (Tabor et al., 2012). AFM force spectroscopy between bubbles and/or droplets gives access to the investigation of DLVO forces responsible for colloidal stability, i.e., van der Waals and coulombic (or electrostatic) forces, as well as non-DLVO forces such as hydrophobic attraction and hydrophilic (steric) repulsion, depending on the composition of the interface. Hydrodynamic thinning of the interfacial film (drainage) and/or coalescence can also be investigated using AFM colloidal force spectroscopy experiments (Gunning et al., 2013). In food systems, the technique has helped determine local forces and fluxes upon approach of oil-in-water or water-in-oil emulsion droplets coated with whey proteins, sugar beet pectin or food-grade polyglycerol polyricinoleate (Gromer, Penfold, Gunning, Kirby, \& Morris, 2010; Gunning et al., 2004; Mettu, Wu, \& Dagastine, 2018). A dwell time can be introduced to keep the two objects in contact at constant load and to positively correlate drainage of the interfacial thin film with the mobility of the surfactant molecule, including milk proteins (Gunning et al., 2013). Comparatively less research has been reported on bubble/bubble interactions. Interaction forces between foam bubbles stabilized with $\mathrm{pH}$-switchable peptides were measured using AFM upon $\mathrm{pH}$ change or introduction of ions in the system (Balasuriya \& Dagastine, 2012).

\subsection{Steric repulsion by a polymer brush}

Among repulsion forces exerted between colloids, that of steric hindrance by polymer brushes has raised interest in the field of AFM force spectroscopy. Mathematical models were developed for the indentation of a polymer brush by a conical or a colloidal AFM tip (Cuellar, Llarena, Moya, \& Donath, 2013). A reference force curve is measured onto a bare spot of the sample, made by locally scratching and clearing the polymer brush with the AFM tip, to get to the contact point. Repulsion exerted by polymer brushes with various $\mathrm{pH}$ and ionic strengths was measured using AFM force spectroscopy to design antifouling surfaces for biological applications, including food (Monchaux \& Vermette, 2007). Others have investigated the ion-pair interaction of facing brushes of oppositely charged polyelectrolytes (Spruijt, Cohen Stuart, \& van der Gucht, 2010) that are implicated in coacervation (Gucht, Spruijt, Lemmers, \& Cohen Stuart, 2011) as can occur in foodstuff (Moschakis \& Biliaderis, 2017). As an application of the droplet/droplet set-up described in section 4.4, Manor et al. (2012) have measured the steric effect of a brush of propylene oxide/ethylene oxide polymers at the surface of mineral oil droplets. Such experiment could find application in food systems, where large colloids such as the milk fat globule or ropy lactic bacteria are enveloped with a thick glycocalyx.

\subsection{Breakthrough force}

In addition to depletion flocculation (Fig. 7 C(3), the rupture of thin films using an AFM tip has been used for the investigation of polar lipid membranes (Alessandrini \& Facci, 2012; Garcia-Manyes \& Sanz, 2010; Redondo-Morata, Giannotti, \& Sanz, 2014). In these experiments, the applied load is increased to the point when the membrane yields, resulting in the occurrence of a "break-through" or "jump-in" event in the approach force curve (Fig. 4(4). Due to fast lateral diffusion and local fluctuations of the intermolecular distances in the membrane, the formation of a hole under the tip has a given relaxation time and energy barrier that decrease with increasing gradients of lateral (spreading) pressure and intermolecular distance that push the molecules outward (Butt \& Franz, 2002; Franz, Loi, Müller, Bamberg, \& Butt, 2002; GarciaManyes \& Sanz, 2010). From this, the retrieved breakthrough force $F_{B}$ is indicative of the local mechanical stability of the membrane, with nanoscale lateral resolution. This value increases with the tip's radius, thermodynamically increases with the loading rate and increases in the presence of ions that may bridge polar lipids together (Alessandrini, Seeger, Di Cerbo, Caramaschi, \& Facci, 2011; Redondo-Morata et al., 2014; Sullan, Li, Hao, Walker, \& Zou, 2010). Furthermore, the jump-in distance may be used to evaluate the membrane's thickness locally, owing that the breakthrough occurs prior to significant deformation (Alessandrini \& Facci, 2012, Fig. 8). This technique has allowed investigation of the nanomechanical properties of bilayer membranes incorporating milk polar lipid extracts (Murthy et al., 2016a; 2016b), milk or egg sphingomyelin or ceramides, with or without cholesterol (Bhojoo, Chen, \& Zou, 2018; García-Arribas, Busto, Alonso, \& Goñi, 2015; Guyomarc'h et al., 2014; Sullan, Li, \& Zou, 2009), fish or plant polar lipid extracts (Jacquot et al., 2014). The local breakthrough force 


\section{A. Individual force curves}

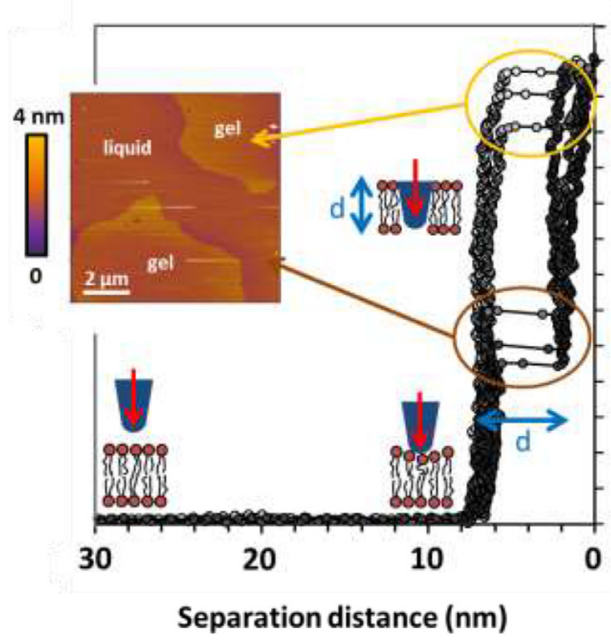

B. Breakthrough force map

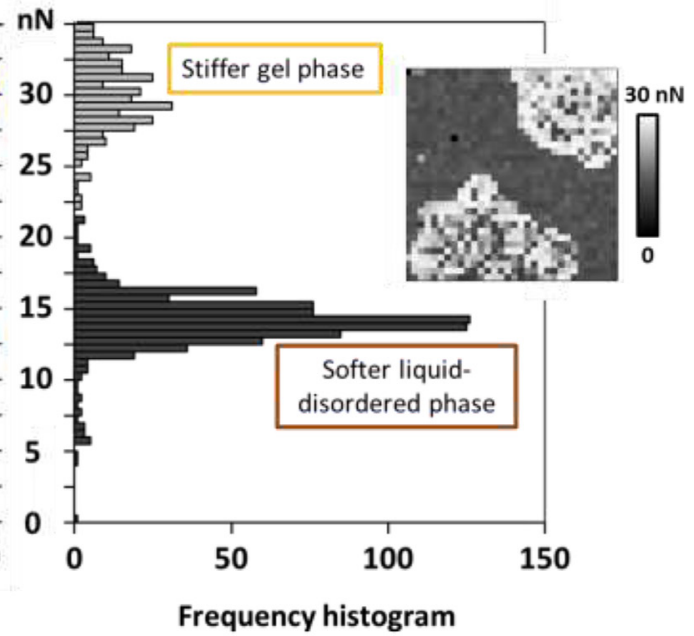

Fig. 8. AFM measurement of the breakthrough force $F_{B}$ on supported lipid bilayers in liquid environment: example of bilayers of polar lipid extract of the milk fat globule membrane (Murthy, Guyomarc'h, \& Lopez, 2016b). (A) Examples of approach force curves taken either on the gel phase domains, mainly composed of milk sphingomyelin (light grey curves and yellow circle) or on the continuous phase, mainly composed of polar lipids in the fluid state (dark grey curves and brown circle). The two phases are visible on the topography image (insert). Sketches show the position of the tip relative to the bilayer at each stage of the force curve and $d$ is the bilayer's thickness evaluated with this method. (B) Breakthrough force map (insert) and breakthrough force histogram measured on the same area as the topography image, evidencing a correspondence between structural features of the biphasic bilayer and mechanical contrast of the gel $v s$ fluid phases. (For interpretation of the references to color in this figure legend, the reader is referred to the Web version of this article.) and thickness values of the bilayer membrane depend on the phase state of the polar lipids. Ordered phases, such as the gel or liquid-ordered phases, are $0.7-1 \mathrm{~nm}$ thicker and rupture at 2-4 times higher forces than liquid-disordered phases at a given temperature. Values usually range in the $\mathrm{nN}$ to tens of $\mathrm{nN}$ depending on lipid composition, temperature and ionic environment. Furthermore, one phase tends to rupture at slightly lower forces with increasing temperature, due to molecular agitation (Garcia-Manyes, Oncins, \& Sanz, 2005). The gel-tofluid phase transition can be monitored using force spectroscopy (Alessandrini \& Facci, 2014). To date, the use of breakthrough force measurement on other food systems is limited. Balasuriya et al. (2012) or Luo et al. (2015, personal communication) have used it with entire milk fat globules. A milk fat globule membrane thickness of about $20 \mathrm{~nm}$ was reported, with extremely low breakthrough forces values of $<0.5 \mathrm{nN}$. Recent AFM developments allowed $\mathrm{F}_{\mathrm{B}}$ measurement through a polymer thin film at a water/heptane interface (Costa et al., 2017), opening the possibility of studying, e.g., protein or polar lipid interfaces in emulsions. Alternatively, breakthrough can be monitored with AFM as a function of time, rather than force, to investigate in detail failure dynamics of biological thin films. This "force-clamp" approach was used to calculate kinetic parameters and the energy barrier of puncturing supported dipalmitoylphosphatidylcholine bilayers (Redondo-Morata, Giannotti, \& Sanz, 2012).

\subsection{Adhesion}

The retraction section of the force curve can also provide information about physical adhesion between the tip and substrate (this section) or with the extension of targeted single molecules (section 5). Adhesion may be characterized by the adhesion force (absolute maximum of the peaks) and/or the adhesion work (area between the retraction curve and the zero-deflection baseline - Chen, Busscher, van der Mei, \& Norde, 2011; Obeid et al., 2019a; Xu \& Logan, 2005). With this approach, the colloidal probe technique (section 4.3) was used to measure the adhesion between a BSA-coated probe and lysozyme or dextran deposited on a substrate (Singh et al., 2015; Xu \& Logan, 2005) or between a BSA-coated probe and different ultrafiltration membranes (Richard Bowen, Hilal, Lovitt, \& Wright, 1999). Colloidal probes coated with milk proteins, milk fat globule membrane fragments or mucin have allowed significant advances in quantifying their adhesion onto probiotic bacteria surfaces (Burgain et al., 2015, 2014a; Gomand et al.,
2019; Guerin et al., 2016) or on cell surfaces (Guerin et al., 2018). These various studies by the LIBio (Nancy, France) has gone into the detail of evaluating adhesion between milk protein or milk fat globule membrane and various motifs of the bacterial surface such as pili or exopolysaccharide. Using the same approach, adhesion between milk fat globules and milk proteins was found to increase with acidification, homogenization and/or forewarming, in agreement with variations of the system (Obeid et al., 2019a, 2020). This confirmed that the adhesion measured between individual structures could account for the macro-rheology of bulk suspensions (Bhosale \& Berg, 2012). Issues of food safety and biofouling may also be investigated using the measurement of adhesion forces between surfaces and bacteria (BinAhmed, Hasane, Wang, Mansurov, \& Romero-Vargas Castrillón, 2018; Shim et al., 2017).

Measurements of single protein-protein adhesion are limited. With this approach, proteins are immobilized both at the tip and onto the surface; sharp tips making it likely that one protein at the extremity of the tip enters in contact with only one counterpart protein on the substrate. In general, the energy required for parting the proteins is less than that of the protein's unfolding energy and ideal constant-velocity experiments yield a single adhesion (or unbinding) peak (Liu et al., 2016). If unfolding occurs prior to unbinding, only the last or "jumpoff" peak is considered (Burgain et al., 2014b; Jin, Lafer, Peng, Smith, \& Nossal, 2013). Among food proteins, the interaction between two cruciferin or napin plant proteins was measured this way (Fahs \& Louarn, 2013). Protein-protein unbinding kinetics can alternatively be measured as a function of time using a constant pulling force (or force clamp). This approach has not been used on food systems (Manibog, Yen, \& Sivasankar, 2017). In other cases, the AFM tip was functionalized with methyls, hydroxyls or other groups to measure the adhesion of proteins (Fahs \& Louarn, 2013), bacteria (Dorobantu, Bhattacharjee, Foght, \& Gray, 2008) or Saccharomyces cerevisiae yeast (Ahimou, Denis, Touhami, \& Dufrene, 2002) to hydrophilic or hydrophobic surfaces. The grafting of bacteria or cells onto AFM tips to measure their adhesion to surfaces (Beaussart et al., 2014; Friedrichs et al., 2013) or to other bacteria (Formosa-Dague et al., 2016) has also been done. Food-related examples are the measurement of the adhesion of Lactococcus lactis to mucins (Le, Guerardel, Loubiere, Mercier-Bonin, \& Dague, 2011), of Lactobacillus rhamnosus to milk proteins (Burgain et al., 2013) or of $S$. cerevisiae to filtration membranes (Richard Bowen et al., 1999). 
(A) Formation of the polymer extension peaks on the retract force curve

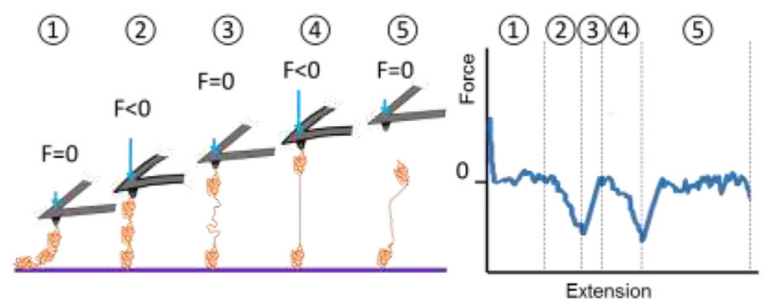

(B) Molecular recognition: example of antigen-antibody unbinding

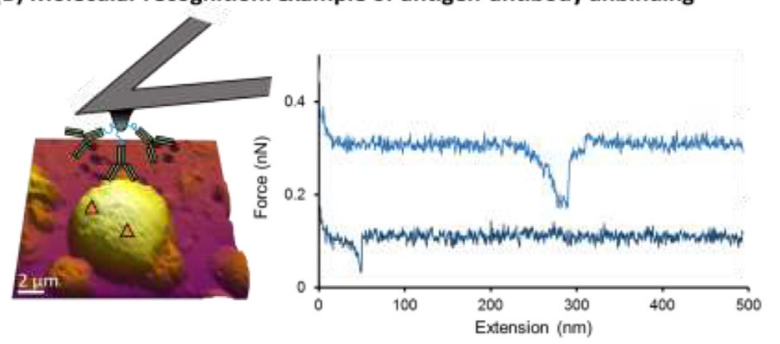

(C) Unfolding of globular protein : example of lactoferrin

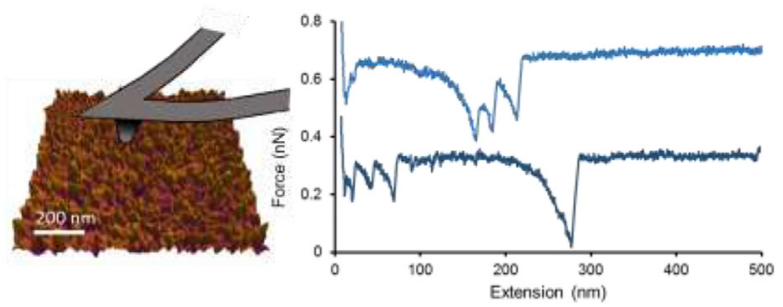

(D) Extension of polysacchride : example of bacterial EPS
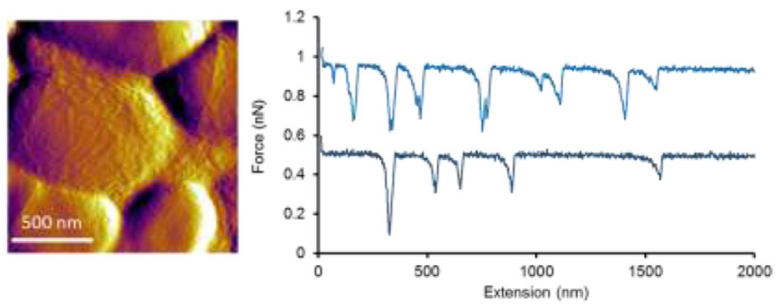

Fig. 9. Single molecule force spectroscopy. (A) General principle of the formation of unfolding or rupture peaks on the retraction curve upon stretching of a polymer molecule. Numbers (1), (2), (3), (4) and (5) refer to the successive events occurring upon retraction (left) and the corresponding responses on the force curve (right). (B-D) Examples of single molecule force spectroscopy experiments during (B) detection of butyrophilin on the surface of a milk fat globule by anti-butyrophilin monoclonal antibody attached to the AFM tip (Obeid, personal communication), (C) unfolding of lactoferrin attached to flat goldcoated substrate, after $2^{\prime}$ contact with the AFM tip (Grunberger, personal communication) and (D) extension of mannose-containing exopolysaccharide (EPS) present at the surface of Propionibacterium freudenreichii CIRM BIA 2289 and targeted with an AFM tip grafted with concanavalin-A lectin (Guyomarc'h et al., in preparation). (For interpretation of the references to color in this figure legend, the reader is referred to the Web version of this article.)

\section{Probing specific interactions: single molecule force spectroscopy}

The retraction curve can also provide specific information on the molecules involved in the interaction. Tips decorated with ligands directed to one target on the sample will allow its localization upon force mapping of the sample (Dufrene, 2004; Francius et al., 2009; Müller, Krieg, Alsteens, \& Dufrêne, 2009; Senapati \& Lindsay, 2016). If adhesion between the molecules is strong, the pulling force exerted by the retracting AFM probe induces their extension or unfolding (Fig. 9 A).
Force spectra then show multiple peaks that correspond to the unfolding of individual monomers or secondary structures in the polymers, from which structural information can be inferred (Marszalek \& Dufrêne, 2012; Rico, Rigato, Picas, \& Scheuring, 2013), up to the point where tip and sample part. Following are some examples of these approaches for food-related systems.

\subsection{Molecular recognition}

In some applications, a chosen lectin is grafted onto AFM tips to localize target-containing polysaccharides on the bacterial wall or pili of L. rhamnosus bacteria (Francius et al., 2009, 2008; Tytgat et al., 2016). Force spectroscopy measurements between a microorganism (on the tip) and a dendritic cell-specific intercellular adhesion molecule-3grabbing non-integrin receptor (DC-SIGN; on the surface) is also possible to determine pathways to pathogenicity (te Riet, ReinierenBeeren, Figdor, \& Cambi, 2015) or probiotic activity (Tytgat et al., 2016). However, no attempt has been reported where a single DC-SIGN receptors would be grafted onto the tip to track signaling sugars at the surface of food bacteria. A grafted immunoglobulin $\mathrm{G}$ tip has been successfully used to detect Protein A on the surface of live Staphylococcus aureus (Touhami, Jericho, \& Beveridge, 2007). Carboxymethylamylose was used as a linker between the $\operatorname{IgG}$ and the tip to allow orientation freedom. The recognition of sphingomyelin in milk polar lipid membranes or possibly onto milk fat globules might be done using the lysenin toxin grafted onto AFM tips, as illustrated on model systems (Wang, Shogomori, Hara, Yamada, \& Kobayashi, 2012). Finally, the use of AFM single molecule force spectroscopy to detect toxins on food sample surfaces has been described (Alexander Reese \& $\mathrm{Xu}, 2019)$. Retraction curves for ligand-receptor interactions usually show one single rupture peak, at a distance dependent on the maximal extension of the linker(s) (Fig. 9 B).

\subsection{Protein unfolding}

The unfolding of single proteins is a difficult experiment to implement and interpret, because of the small dimensions of proteins or of their secondary or ternary structures. After immobilization onto mica (Touhami \& Dutcher, 2009) or onto gold (Fahs \& Louarn, 2013), it is possible to unfold a single $\beta$-lactoglobulin, napin or cruciferin with a silicon nitride AFM tip pressed against the protein for $0.5-5 \mathrm{~s}$, then retracted. It is also possible to graft the protein onto the AFM tip, to press it against gold and pull it (Fahs \& Louarn, 2013). Retraction curves then show a sawtooth pattern (Fig. 9 C) where the last peak indicates rupture between the tip and the protein (detachment at maximal length $\mathrm{L}_{\max }$ ) and intermediate peaks represent unfolding of the protein's weakest structural elements, e.g., domains, loops or segments in contact with the substrate. The distance between two consecutive peaks indicates the length of the unfolded element, and not all domains may be extended if detachment occurs first (Fahs \& Louarn, 2013). When $\beta$-lactoglobulin is immobilized at the surface of an oil droplet, it partially denatures to fit at the oil/water interface. Stretching $\beta$-lactoglobulin with an AFM tip then requires lower force and unfolds shorter (residual) domains (Touhami et al., 2011).

\subsection{Polymer extension}

The stretching of polysaccharide or polyprotein polymers are the most common studies using AFM single molecule force spectroscopy. When sawtooth events are expected to represent the successive extensions of a series of protein monomers, the worm like chain (or WLC) model has been successfully applied to yield the contour length $\left(L_{c}\right)$ and persistence length $\left(l_{p}\right)$ at each unfolding step (Rico et al., 2013), $L_{c}$ being the length of the linearly extended molecule ( $L_{\max }$ when all monomers are unfolded). The persistence length $l_{p}$ of the molecule is the distance over which correlation with the direction of the tangent to 


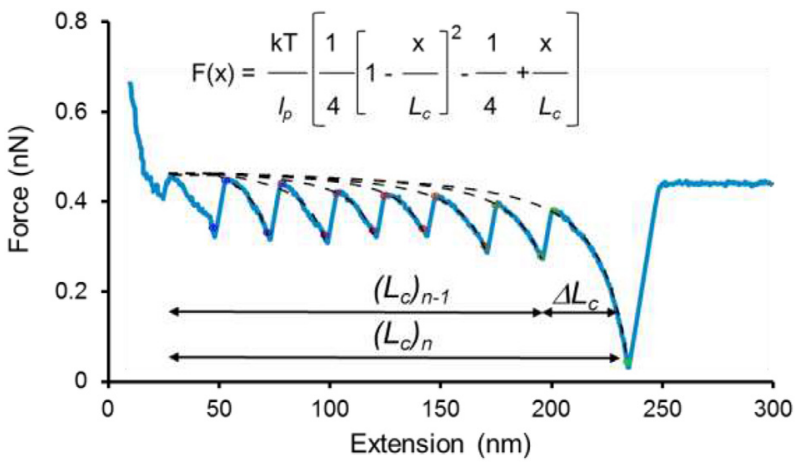

Fig. 10. The worm like chain (WLC) model applied to the unfolding of titin (courtesy of Asylum Research, Oxford Instruments, Santa Barbara, CA, USA). Each unfolding event is fitted with the WLC model to yield the contour length, $L_{c}$, and the persistence length, $l_{p}$, at each unfolding step. The final $L_{c}$ is that of the fully stretched polymer. $\Delta L_{c}$ is the length of the unfolded segment. $\mathrm{T}$ is the absolute temperature and $\mathrm{k}$ the Boltzmann constant (as distinguished from the stiffness $k$ elsewhere in the text).

the molecule's backbone is lost. It is indicative of the flexibility of a polymer: the larger the $l_{p}$, the stiffer the polymer. The "archetypal" example of this approach is that of titin, a large muscle protein with multiply repeated immunoglobulin-like domains (Rief, 1997; Tskhovrebova, Trinick, Sleep, \& Simmons, 1997, Fig. 10). AFM extension of a polyprotein construct of bacteriophage T4 lysozyme (Yang et al., 2000) is another good example of this application. They show that detailed protein unfolding behavior could be obtained through constructing polymeric series of a food protein or of a targeted domain of a food protein, e.g., to predict their denaturation behavior upon heating or exposure to an interface.

The extension of polysaccharides is better described by the freely jointed chain (FJC) model and derivatives (Marszalek \& Dufrêne, 2012), where the polymer is modeled as a series of Kuhn segments with length $l_{k}\left(l_{k}=2 l_{p}\right)$ and stiffness $k_{s}$, for a contour length $L_{c}$ as in the WLC model. When putting AFM colloidal probes grafted with milk proteins in contact with L. rhamnosus GG, applying the WLC and FJC models sequentially helps identify cell-wall glycoproteins as the type of molecules responsible for adhesion (Burgain et al., 2014a; Guerin et al., 2016). When using lectin-grafted AFM probes, targeting sugar units of, e.g., bacterial polysaccharides, the FJC model is used to infer structural information (Francius et al., 2008; Guyomarc'h et al., in preparation Fig. 9 D). Finally, the approach has proven useful to stretch bacterial pili. The bacteria may be grafted onto the AFM tip, pushed against mica and retracted (Touhami, Jericho, Boyd, \& Beveridge, 2006) or immobilized onto substrates and challenged with protein-coated AFM probes to investigate adhesion mechanisms between pili of L. rhamnosus and whey proteins (Burgain et al., 2015, 2014a; Guerin et al., 2016).

\section{Perspectives}

Food science has benefited from technological implementations of AFM methods developed for cell biology, microbiology, colloids or material physics. In this last section, future possible transfers are identified.

A major limitation of AFM is that no direct component identification is possible in complex systems. Therefore, research has focused on coupling AFM imaging with high spatial resolution spectroscopy techniques for biological objects, mostly cells (Kainz, Oprzeska-Zingrebe, \& Herrera, 2014). In systems closer to food, coupling AFM with confocal laser scanning microscopy (CLSM) was used to interpret force curves between facing oil droplets with a complementary measure of interdroplet distance (Tabor et al., 2011, Fig. 7) or to correlate oil-gelatin emulsion network structure with nanomechanical AFM indentation experiments (Filip et al., 2006). Protein fibers or fibrillation have been observed, e.g., in cytoskeleton or other structures using coupled AFM and super-resolution optical microscopies (Chacko, Zanacchi, \& Diaspro, 2013; Cosentino, Canale, Bianchini, \& Diaspro, 2019; Janel, Werkmeister, Bongiovanni, Lafont, \& Barois, 2017), coupled AFM and total internal reflection fluorescence microscopy (TIRFM - Fukuda et al., 2013) or using coupled AFM and transmission electron microscopy (TEM - Yamada, Konno, \& Shimabukuro, 2017). Protein identification or structures were investigated using coupled AFM and infrared spectroscopy (Ji et al., 2019; Paluszkiewicz et al., 2017) or using coupled AFM and mass spectroscopy using heated cantilevers (Andrade, Silva, Azevedo, Cunha, \& Sousa, 2006; de Vries, 2015; Somnath, Jesse, Van Berkel, Kalinin, \& Ovchinnikova, 2016). Coupling AFM with epifluorescence or with either surface- or tip-enhanced Raman spectroscopy has opened perspectives for the molecular recognition of polar lipids and inserted molecules such as cholesterol or peptides in supported bilayers (Bhatia et al., 2014; Opilik, Bauer, Schmid, Stadler, \& Zenobi, 2011; Sweetenham, Larraona-Puy, \& Notingher, 2011; Treffer et al., 2012). The coupling between AFM and grazing incidence X-ray reflectivity has been undertaken at the European Radiation Synchrotron Facility (Grenoble, France) and tested on lipid bilayers (Gumí-Audenis et al., 2015).

Another interesting possibility of AFM for food science is the recent developments of high-speed imaging, to investigate dynamics in, e.g., membrane protein arrangements, protein unfolding, protein docking or changes in bacterial surfaces (Ando, Uchihashi, \& Scheuring, 2014; Eghiaian, Rico, Colom, Casuso, \& Scheuring, 2014). Alternatively, cryoAFM reduces the thermal noise and slows the thermal dynamics of macromolecules using low temperatures, e.g., in liquid nitrogen or helium vapor, which provides access to highly mobile structures with higher resolution than that attained at room temperature (Shao \& Zhang, 1996). It has been used on actin or myosin fibers (Shao, Shi, \& Somlyo, 2000; Sheng et al., 2003). These applications could be used to detail in the interfacial or unfolding behavior of food proteins, to follow fast lipid and/or protein assemblies at surfaces, or to monitor alteration of lipid membranes or bacterial surfaces by enzymes, surfactants or peptides.

\section{Conclusions}

Since its beginning in the late 1980s, the AFM technique has steadily expanded in various fields. Thanks to its ability to accommodate the liquid environment and environmental changes, AFM imaging found applications in biology, where the correlation of imaging with nanomechanics was used by biophysicists (Parot et al., 2007). However, life science applications of AFM essentially turned to cellular biology and microbiology, mostly for medical questions (Pellequer et al., 2019). As pointed out by Yang et al., in 2007, the technique has comparatively not yet reached its full potential in food science (Fig. 11).

Hopefully, the present review will show that opportunities of technical transfers from cell biology, microbiology or biophysical applications of AFM to food systems are plentiful, with the prospect of showing more about the architecture of foodstuff down to the nanoscale. Evidence is accumulating that many structural or textural qualities of food, appreciated at the macroscale, need to be investigated at the scale of its building blocks to be understood and controlled. With enough investment to set up sample immobilization and experimental conditions, AFM may be a most interesting technique to tackle these challenges.

\section{Declaration of competing interest}

Authors declare no conflict of interest. 


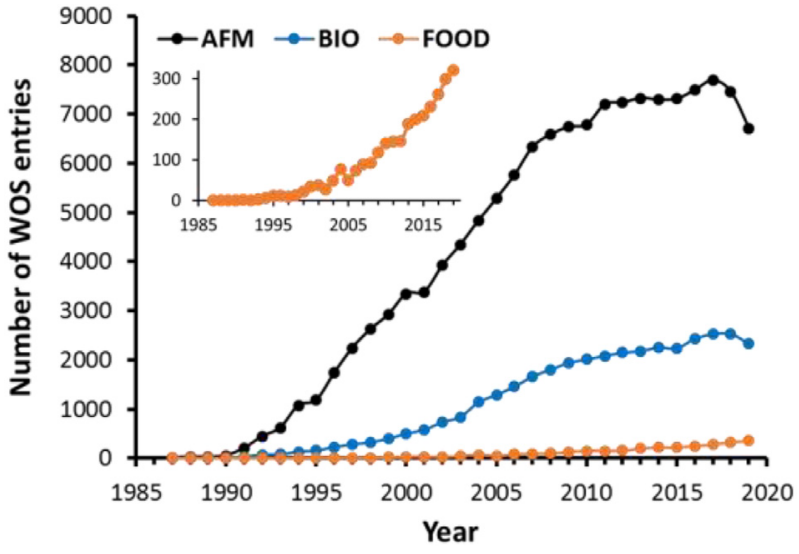

Fig. 11. Evolution of the number of scientific papers recorded in the Web of Science (WOS) database from 1985 to 2019. AFM or BIO respectively stand for all atomic force microscopy entries or for entries where AFM is used for biological applications, using the same search as in Parot et al. (2007), only that "microscopy" is replaced by "microscop". FOOD is the result of the following search: ('atomic force microscop"' AND food) OR ('atomic force microscop"' AND milk) OR ('atomic force microscop*' AND egg) OR ('atomic force microscop*' AND plant) OR ('atomic force microscop*' AND fish) OR ('atomic force microscop"' AND fruit) OR ('atomic force microscop*' AND meat)

\section{Acknowledgements}

Author Fanny Guyomarc'h deeply acknowledges all the indoor or outdoor permanent and temporary staff colleagues who contributed to STLO's experience of AFM. STLO's Asylum Research MFP3D-BIO atomic force microscope was funded by the European Union (FEDER), the French Ministry of Education and Research, INRA, the Conseil Général 35 and Rennes Métropole.

\section{References}

Adal, E., Sadeghpour, A., Connell, S., Rappolt, M., Ibanoglu, E., \& Sarkar, A. (2017). Heteroprotein complex Formation of bovine lactoferrin and pea protein isolate: A multiscale structural analysis. Biomacromolecules, 18, 625-635. https://doi.org/10. 1021/acs.biomac.6b01857.

Ahimou, F., Denis, F. A., Touhami, A., \& Dufrene, Y. F. (2002). Probing microbial cell surface charges by atomic force microscopy. Langmuir, 18, 9937-9941. https://doi. org/10.1021/la026273k

Ahmed, N., Nino, D. F., \& Moy, V. T. (2001). Measurement of solution viscosity by atomic force microscopy. Review of Scientific Instruments, 72, 2731-2734. https://doi.org/10. $1063 / 1.1368856$.

Alessandrini, A., \& Facci, P. (2011). Unraveling lipid/protein interaction in model lipid bilayers by atomic force microscopy. Journal of Molecular Recognition, 24, 387-396. https://doi.org/10.1002/jmr.1083.

Alessandrini, A., \& Facci, P. (2012). Nanoscale mechanical properties of lipid bilayers and their relevance in biomembrane organization and function. Micron, 43, 1212-1223. https://doi.org/10.1016/j.micron.2012.03.013.

Alessandrini, A., \& Facci, P. (2014). Phase transitions in supported lipid bilayers studied by AFM. Soft Matter, 10, 7145-7164. https://doi.org/10.1039/C4SM01104J.

Alessandrini, A., Seeger, H. M., Di Cerbo, A., Caramaschi, T., \& Facci, P. (2011). What do we really measure in AFM punch-through experiments on supported lipid bilayers? Soft Matter, 7, 7054-7064. https://doi.org/10.1039/c1sm05453h.

Alexander Reese, R., \& Xu, B. (2019). Single-molecule detection of proteins and toxins in food using atomic force microscopy. Trends in Food Science \& Technology, 87, 26-34. https://doi.org/10.1016/j.tifs.2019.03.031.

Ando, T., Uchihashi, T., \& Kodera, N. (2013). High-speed AFM and applications to biomolecular systems. Annual Review of Biophysics, 42, 393-414. https://doi.org/10. 1146/annurev-biophys-083012-130324.

Ando, T., Uchihashi, T., \& Scheuring, S. (2014). Filming biomolecular processes by highspeed atomic force microscopy. Chemical Reviews, 114, 3120-3188. https://doi.org/ 10.1021/cr4003837.

Andrade, A. C., Silva, L. P., Azevedo, R. B., Cunha, R. B., \& Sousa, M. V. (2006). AFM-MS, atomic force microscopy coupled to mass spectrometry for protein analysis. Molecular \& Cellular Proteomics, 5 S271-S271.

Arfsten, J., Leupold, S., Bradtmöller, C., Kampen, I., \& Kwade, A. (2010). Atomic force microscopy studies on the nanomechanical properties of Saccharomyces cerevisiae. Colloids and Surfaces B: Biointerfaces, 79, 284-290. https://doi.org/10.1016/j. colsurfb.2010.04.011.

Attard, P., \& Miklavcic, S. J. (2001). Effective spring constant of bubbles and droplets. Langmuir, 17, 8217-8223. https://doi.org/10.1021/la010969g.
Bahri, A., Martin, M., Gergely, C., Marchesseau, S., \& Chevalier-Lucia, D. (2018). Topographical and nanomechanical characterization of casein nanogel particles using atomic force microscopy. Food Hydrocolloids, 83, 53-60. https://doi.org/10.1016/j. foodhyd.2018.03.029.

Bahri, A., Martin, M., Gergely, C., Pugnière, M., Chevalier-Lucia, D., \& Marchesseau, S. (2017). Atomic force microscopy study of the topography and nanomechanics of casein micelles captured by an antibody. Langmuir, 33, 4720-4728. https://doi.org/ 10.1021/acs.langmuir.7b00311.

Balasuriya, T. S., \& Dagastine, R. R. (2012). Interaction forces between bubbles in the presence of novel responsive peptide surfactants. Langmuir, 28, 17230-17237. https://doi.org/10.1021/la304351a.

Balasuriya, T. S., Ong, L., Gras, S. L., \& Dagastine, R. R. (2012). Changes in morphological and nano-mechanical properties of the milk fat globule membrane during processing. RSC Advances, 2, 2384-2394. https://doi.org/10.1039/c2ra00844k.

Beaussart, A., El-Kirat-Chatel, S., Sullan, R. M. A., Alsteens, D., Herman, P., Derclaye, S., et al. (2014). Quantifying the forces guiding microbial cell adhesion using single-cell force spectroscopy. Nature Protocols, 9, 1049-1055. https://doi.org/10.1038/nprot. 2014.066.

Berry, J. D., Mettu, S., \& Dagastine, R. R. (2017). Precise measurements of capsule mechanical properties using indentation. Soft Matter, 13, 1943-1947. https://doi.org/ 10.1039/C6SM02841A.

Berton-Carabin, C., Genot, C., Gaillard, C., Guibert, D., \& Ropers, M. H. (2013). Design of interfacial films to control lipid oxidation in oil-in-water emulsions. Food Hydrocolloids, 33, 99-105. https://doi.org/10.1016/j.foodhyd.2013.02.021.

Berton-Carabin, C., Sagis, L., \& Schroën, K. (2018). Formation, structure, and functionality of interfacial layers in food emulsions. Annual Review of Food Science and Technology, 9, 551-587. https://doi.org/10.1146/annurev-food-030117-012405.

Bhatia, T., Husen, P., Ipsen, J. H., Bagatolli, L. A., \& Simonsen, A. C. (2014). Fluid domain patterns in free-standing membranes captured on a solid support. Biochimica et Biophysica Acta (BBA) - Biomembranes, 1838, 2503-2510. https://doi.org/10.1016/j. bbamem.2014.05.016.

Bhojoo, U., Chen, M., \& Zou, S. (2018). Temperature induced lipid membrane restructuring and changes in nanomechanics. Biochimica et Biophysica Acta (BBA) Biomembranes, 1860, 700-709. https://doi.org/10.1016/j.bbamem.2017.12.008.

Bhosale, P. S., \& Berg, J. C. (2012). The dynamics of polymer bridge formation and disruption and its effect on the bulk rheology of suspensions. Langmuir, 28, 16807-16811. https://doi.org/10.1021/la3039297.

BinAhmed, S., Hasane, A., Wang, Z., Mansurov, A., \& Romero-Vargas Castrillón, S. (2018). Bacterial adhesion to ultrafiltration membranes: Role of hydrophilicity, natural organic matter, and cell-surface macromolecules. Environmental Science \& Technology, 52, 162-172. https://doi.org/10.1021/acs.est.7b03682.

Binnig, G., Quate, C. F., \& Gerber, C. (1986). Atomic force microscope. Physical Review Letters, 56, 930-933. https://doi.org/10.1103/PhysRevLett.56.930.

Bolisetty, S., Adamcik, J., \& Mezzenga, R. (2011). Snapshots of fibrillation and aggregation kinetics in multistranded amyloid $\beta$-lactoglobulin fibrils. Soft Matter, 7, 493-499. https://doi.org/10.1039/COSM00502A.

Bonaccurso, E., \& Butt, H.-J. (2005). Microdrops on atomic force microscope cantilevers: Evaporation of water and spring constant calibration. The Journal of Physical Chemistry B, 109, 253-263. https://doi.org/10.1021/jp0471406.

Bourlieu, C., Paboeuf, G., Chever, S., Pezennec, S., Cavalier, J.-F., Guyomarc'h, F., et al. (2016). Adsorption of gastric lipase onto multicomponent model lipid monolayers with phase separation. Colloids and Surfaces B: Biointerfaces, 143, 97-106. https://doi. org/10.1016/j.colsurfb.2016.03.032.

Buchner Santos, E., Morris, J. K., Glynos, E., Sboros, V., \& Koutsos, V. (2012). Nanomechanical properties of phospholipid microbubbles. Langmuir, 28, 5753-5760. https://doi.org/10.1021/la204801u.

Bui, V. C., Kim, Y. U., \& Choi, S. S. (2008). Physical characteristics of Saccharomyces cerevisiae. Surface and Interface Analysis, 40, 1323-1327. https://doi.org/10.1002/sia. 2899.

Burgain, J., Gaiani, C., Francius, G., Revol-Junelles, A. M., Cailliez-Grimal, C., Lebeer, S., et al. (2013). In vitro interactions between probiotic bacteria and milk proteins probed by atomic force microscopy. Colloids and Surfaces B: Biointerfaces, 104, 153-162. https://doi.org/10.1016/j.colsurfb.2012.11.032.

Burgain, J., Scher, J., Francius, G., Borges, F., Corgneau, M., Revol-Junelles, A. M., et al. (2014b). Lactic acid bacteria in dairy food: Surface characterization and interactions with food matrix components. Advances in Colloid and Interface Science, 213, 21-35. https://doi.org/10.1016/j.cis.2014.09.005.

Burgain, J., Scher, J., Lebeer, S., Vanderleyden, J., Cailliez-Grimal, C., Corgneau, M., et al. (2014a). Significance of bacterial surface molecules interactions with milk proteins to enhance microencapsulation of Lactobacillus rhamnosus GG. Food Hydrocolloids, 41, 60-70. https://doi.org/10.1016/j.foodhyd.2014.03.029.

Burgain, J., Scher, J., Lebeer, S., Vanderleyden, J., Corgneau, M., Guerin, J., et al. (2015) Impacts of $\mathrm{pH}$-mediated EPS structure on probiotic bacterial pili-whey proteins interactions. Colloids and Surfaces B: Biointerfaces, 134, 332-338. https://doi.org/10. 1016/j.colsurfb.2015.06.068.

Burgain, J., Scher, J., Petit, J., Francius, G., \& Gaiani, C. (2016). Links between particle surface hardening and rehydration impairment during micellar casein powder storage. Food Hydrocolloids, 61, 277-285. https://doi.org/10.1016/j.foodhyd.2016.05. 021.

Butt, H.-J. (1991). Measuring electrostatic, van der Waals, and hydration forces in electrolyte solutions with an atomic force microscope. Biophysical Journal, 60, 1438-1444. https://doi.org/10.1016/S0006-3495(91)82180-4.

Butt, H.-J., Cappella, B., \& Kappl, M. (2005). Force measurements with the atomic force microscope: Technique, interpretation and applications. Surface Science Reports, 59. https://doi.org/10.1016/j.surfrep.2005.08.003 1-152.

Butt, H.-J., \& Franz, V. (2002). Rupture of molecular thin films observed in atomic force 
microscopy. I. Theory. Physical Review E, 66, 031601. https://doi.org/10.1103/ PhysRevE.66.031601.

Čadež, V., Erceg, I., Selmani, A., Domazet Jurašin, D., Šegota, S., Lyons, D., et al. (2018). Amorphous calcium phosphate formation and aggregation process revealed by light scattering techniques. Crystals, 8, 254. https://doi.org/10.3390/cryst8060254.

Camesano, T. A., \& Logan, B. E. (2000). Probing bacterial electrosteric interactions using atomic force microscopy. Environmental Science \& Technology, 34, 3354-3362. https://doi.org/10.1021/es9913176.

Cárdenas-Pérez, S., Chanona-Pérez, J. J., Méndez-Méndez, J. V., Arzate-Vázquez, I., Hernández-Varela, J. D., \& Vera, N. G. (2019). Recent advances in atomic force microscopy for assessing the nanomechanical properties of food materials. Trends in Food Science \& Technology, 87, 59-72. https://doi.org/10.1016/j.tifs.2018.04.011.

Chacko, J. V., Zanacchi, F. C., \& Diaspro, A. (2013). Probing cytoskeletal structures by coupling optical superresolution and AFM techniques for a correlative approach: Probing cytoskeletal structures. Cytoskeleton, 70, 729-740. https://doi.org/10.1002/ cm.21139.

Chen, Y., Busscher, H. J., van der Mei, H. C., \& Norde, W. (2011). Statistical analysis of long- and short-range forces involved in bacterial adhesion to substratum surfaces as measured using atomic force microscopy. Applied and Environmental Microbiology, 77, 5065-5070. https://doi.org/10.1128/AEM.00502-11.

Chichti, E., George, M., Delenne, J.-Y., Radjai, F., \& Lullien-Pellerin, V. (2013). Nanomechanical properties of starch and gluten biopolymers from atomic force microscopy. European Polymer Journal, 49, 3788-3795. https://doi.org/10.1016/j. eurpolymj.2013.08.024.

Christensen, M., Rasmussen, J. T., \& Simonsen, A. C. (2015). Roughness analysis of single nanoparticles applied to atomic force microscopy images of hydrated casein micelles. Food Hydrocolloids, 45, 168-174. https://doi.org/10.1016/j.foodhyd.2014.11.008.

Connell, S. D., Heath, G., Olmsted, P. D., \& Kisil, A. (2013). Critical point fluctuations in supported lipid membranes. Faraday Discussions, 161, 91-111. https://doi.org/10. 1039/C2FD20119D.

Cosentino, M., Canale, C., Bianchini, P., \& Diaspro, A. (2019). AFM-STED correlative nanoscopy reveals a dark side in fluorescence microscopy imaging. Science Advances, 5, eaav8062. https://doi.org/10.1126/sciadv.aav8062.

Costa, D. O., Allo, B. A., Klassen, R., Hutter, J. L., Dixon, S. J., \& Rizkalla, A. S. (2012), Control of surface topography in biomimetic calcium phosphate coatings. Langmuir, 28, 3871-3880. https://doi.org/10.1021/la203224a.

Costa, L., Li-Destri, G., Pontoni, D., Konovalov, O., \& Thomson, N. H. (2017). Liquidliquid interfacial imaging using atomic force microscopy. Advanced Materials Interfaces, 4, 1700203. https://doi.org/10.1002/admi.201700203.

Costa, L., Li-Destri, G., Thomson, N. H., Konovalov, O., \& Pontoni, D. (2016). Real space imaging of nanoparticle assembly at liquid-liquid interfaces with nanoscale resolution. Nano Letters, 16, 5463-5468. https://doi.org/10.1021/acs.nanolett.6b01877.

Crespo-Villanueva, A., Gumí-Audenis, B., Sanz, F., Artzner, F., Mériadec, C., Rousseau, F., et al. (2018). Casein interaction with lipid membranes: Are the phase state or charge density of the phospholipids affecting protein adsorption? Biochimica et Biophysica Acta (BBA) - Biomembranes, 1860, 2588-2598. https://doi.org/10.1016/j.bbamem. 2018.09.016.

Cuellar, J. L., Llarena, I., Moya, S. E., \& Donath, E. (2013). Indentation of highly charged PSPM brushes measured by force spectroscopy: Application of a compressible fluid model. Macromolecules, 46, 2323-2330. https://doi.org/10.1021/ma302562v.

Dagastine, R. R. (2006). Dynamic forces between two deformable oil droplets in water. Science, 313, 210-213. https://doi.org/10.1126/science.1125527.

Dagastine, R. R., Stevens, G. W., Chan, D. Y. C., \& Grieser, F. (2004). Forces between two oil drops in aqueous solution measured by AFM. Journal of Colloid and Interface Science, 273, 339-342. https://doi.org/10.1016/j.jcis.2003.11.001.

Das, C., Sheikh, K. H., Olmsted, P. D., \& Connell, S. D. (2010). Nanoscale mechanical probing of supported lipid bilayers with atomic force microscopy. Physical Review, 82, 041920. https://doi.org/10.1103/PhysRevE.82.041920.

Dauphas, S., Beaumal, V., Gunning, P., Mackie, A., Wilde, P., Vié, V., et al. (2007a). Structure modification in hen egg yolk low density lipoproteins layers between 30 and $45 \mathrm{mN} / \mathrm{m}$ observed by AFM. Colloids and Surfaces B: Biointerfaces, 54, 241-248. https://doi.org/10.1016/j.colsurfb.2006.10.027.

Dauphas, S., Beaumal, V., Gunning, P., Mackie, A., Wilde, P., Vié, V., et al. (2007b). Structures and rheological properties of hen egg yolk low density lipoprotein layers spread at the air-water interface at $\mathrm{pH} 3$ and 7. Colloids and Surfaces B: Biointerfaces, 57, 124-133. https://doi.org/10.1016/j.colsurfb.2007.01.017.

Demanèche, S., Chapel, J.-P., Monrozier, L. J., \& Quiquampoix, H. (2009). Dissimilar pHdependent adsorption features of bovine serum albumin and $\alpha$-chymotrypsin on mica probed by AFM. Colloids and Surfaces B: Biointerfaces, 70, 226-231. https://doi.org/ 10.1016/j.colsurfb.2008.12.036.

Derde, M., Guérin-Dubiard, C., Lechevalier, V., Cochet, M.-F., Jan, S., Baron, F., et al. (2014). Dry-heating of lysozyme increases its activity against Escherichia coli membranes. Journal of Agricultural and Food Chemistry, 62, 1692-1700. https://doi.org/ 10.1021/jf405155p.

Dickinson, E. (2015). Microgels - an alternative colloidal ingredient for stabilization of food emulsions. Trends in Food Science \& Technology, 43, 178-188. https://doi.org/ 10.1016/j.tifs.2015.02.006.

Dincer, T. D., Ogden, M. I., \& Parkinson, G. M. (2014). Investigation of growth rate dispersion in lactose crystallisation by AFM. Journal of Crystal Growth, 402, 215-221. https://doi.org/10.1016/j.jcrysgro.2014.06.027.

Ding, M., Shi, C., \& Zhong, J. (2019). Atomic force microscopy for food quality evaluation. In J. Zhong, \& X. Wang (Eds.). Evaluation technologies for food quality (pp. 715741). Cambridge, UK: Woodhead Publishing Books. https://doi.org/10.1016/B9780-12-814217-2.00028-7.

Doherty, S. B., Gee, V. L., Ross, R. P., Stanton, C., Fitzgerald, G. F., \& Brodkorb, A. (2010). Efficacy of whey protein gel networks as potential viability-enhancing scaffolds for cell immobilization of Lactobacillus rhamnosus GG. Journal of Microbiological Methods, 80, 231-241. https://doi.org/10.1016/j.mimet.2009.12.009.

Dorobantu, L. S., Bhattacharjee, S., Foght, J. M., \& Gray, M. R. (2008). Atomic forc microscopy measurement of heterogeneity in bacterial surface hydrophobicity. Langmuir, 24, 4944-4951. https://doi.org/10.1021/la7035295.

Dorobantu, L. S., Goss, G. G., \& Burrell, R. E. (2012). Atomic force microscopy: A nanoscopic view of microbial cell surfaces. Micron, 43, 1312-1322. https://doi.org/10. 1016/j.micron.2012.05.005.

Ducker, W. A., Senden, T. J., \& Pashley, R. M. (1991). Direct measurement of colloidal forces using an atomic force microscope. Nature, 353, 239-241. https://doi.org/10. 1038/353239a0.

Ducker, W. A., Senden, T. J., \& Pashley, R. M. (1992). Measurement of forces in liquids using a force microscope. Langmuir, 8, 1831-1836. https://doi.org/10.1021/ la00043a024.

Dufrene, Y. F. (2004). Using nanotechniques to explore microbial surfaces. Nature Reviews Microbiology, 2, 451-460. https://doi.org/10.1038/nrmicro905.

Dufrêne, Y. F., Ando, T., Garcia, R., Alsteens, D., Martinez-Martin, D., Engel, A., et al. (2017). Imaging modes of atomic force microscopy for application in molecular and cell biology. Nature Nanotechnology, 12, 295-307. https://doi.org/10.1038/nnano. 2017.45.

Dupres, V., Alsteens, D., Andre, G., \& Dufrene, Y. F. (2010). Microbial nanoscopy: A closer look at microbial cell surfaces. Trends in Microbiology, 18, 397-405.

Dupres, V., Alsteens, D., Pauwels, K., \& Dufrene, Y. F. (2009). In vivo imaging of S-layer nanoarrays on Corynebacterium glutamicum. Langmuir, 25, 9653-9655. https://doi. org/10.1021/la902238q.

Eghiaian, F., Rico, F., Colom, A., Casuso, I., \& Scheuring, S. (2014). High-speed atomic force microscopy: Imaging and force spectroscopy. FEBS Letters, 588, 3631-3638. https://doi.org/10.1016/j.febslet.2014.06.028.

Esteban-Ferrer, D., Edwards, M. A., Fumagalli, L., Juárez, A., \& Gomila, G. (2014). Electric polarization properties of single bacteria measured with electrostatic force microscopy. ACS Nano, 8, 9843-9849. https://doi.org/10.1021/nn5041476.

Et-Thakafy, O., Delorme, N., Gaillard, C., Mériadec, C., Artzner, F., Lopez, C., et al. (2017). Mechanical properties of membranes composed of gel-phase or fluid-phase phospholipids probed on liposomes by atomic force spectroscopy. Langmuir, 33, 5117-5126. https://doi.org/10.1021/acs.langmuir.7b00363.

Et-Thakafy, O., Delorme, N., Guyomarc'h, F., \& Lopez, C. (2018). Mechanical properties of milk sphingomyelin bilayer membranes in the gel phase: Effects of naturally complex heterogeneity, saturation and acyl chain length investigated on liposomes using AFM. Chemistry and Physics of Lipids, 210, 47-59. https://doi.org/10.1016/j. chemphyslip.2017.11.014.

Et-Thakafy, O., Guyomarc'h, F., \& Lopez, C. (2019). Young modulus of supported lipid membranes containing milk sphingomyelin in the gel, fluid or liquid-ordered phase, determined using AFM force spectroscopy. Biochimica et Biophysica Acta (BBA) Biomembranes, 1861, 1523-1532. https://doi.org/10.1016/j.bbamem.2019.07.005.

Evangelopoulos, A. E. A. S., Glynos, E., Madani-Grasset, F., \& Koutsos, V. (2012). Elastic modulus of a polymer nanodroplet: Theory and experiment. Langmuir, 28, 4754-4767. https://doi.org/10.1021/la2049037.

Fahs, A., \& Louarn, G. (2013). Plant protein interactions studied using AFM force spectroscopy: Nanomechanical and adhesion properties. Physical Chemistry Chemical Physics, 15, 11339-11348. https://doi.org/10.1039/c3cp51007g.

Fang, T.-H., Kang, S.-H., Hong, Z.-H., \& Wu, C.-D. (2012). Elasticity and nanomechanical response of Aspergillus niger spores using atomic force microscopy. Micron, 43, 407-411. https://doi.org/10.1016/j.micron.2011.10.011.

Farrokhi, F., Badii, F., Ehsani, M. R., \& Hashemi, M. (2019). Functional and thermal properties of nanofibrillated whey protein isolate as functions of denaturation temperature and solution $\mathrm{pH}$. Colloids and Surfaces A: Physicochemical and Engineering Aspects, 583, 124002. https://doi.org/10.1016/j.colsurfa.2019.124002.

Feller, T., Kellermayer, M. S. Z., \& Kiss, B. (2014). Nano-thrombelastography of fibrin during blood plasma clotting. Journal of Structural Biology, 186, 462-471. https://doi. org/10.1016/j.jsb.2014.04.002.

Filip, D., Uricanu, V. I., Duits, M. H. G., Agterof, W. G. M., \& Mellema, J. (2005). Influence of bulk elasticity and interfacial tension on the deformation of gelled water-in-oil emulsion droplets: An AFM study. Langmuir, 21, 115-126. https://doi.org/10.1021/ la048276y.

Filip, D., Uricanu, V. I., Duits, M. H. G., van den Ende, D., Mellema, J., Agterof, W. G. M., et al. (2006). Microrheology of aggregated emulsion droplet networks, studied with AFM - CSLM. Langmuir, 22, 560-574. https://doi.org/10.1021/la0522653.

Finessi, M., Sinha, P., Szilágyi, I., Popa, I., Maroni, P., \& Borkovec, M. (2011). Charge reversal of sulfate latex particles by adsorbed linear poly(ethylene imine) probed by multiparticle colloidal probe technique. The Journal of Physical Chemistry B, 115, 9098-9105. https://doi.org/10.1021/jp203514r.

Formosa-Dague, C., Feuillie, C., Beaussart, A., Derclaye, S., Kucharíková, S., Lasa, I., et al (2016). Sticky matrix: Adhesion mechanism of the staphylococcal polysaccharide intercellular adhesin. ACS Nano, 10, 3443-3452. https://doi.org/10.1021/acsnano. 5 b07515.

Formosa, C., \& Dague, E. (2015). Imaging living yeast cells and quantifying their biophysical properties by atomic force microscopy. In T. E. S. Dahms, \& K. J. Czymmek (Eds.). Advanced microscopy in mycology (pp. 125-141). New York, NY, USA: Springer International Publishing. https://doi.org/10.1007/978-3-319-22437-4 7.

Fotiadis, D. (2012). Atomic force microscopy for the study of membrane proteins. Current Opinion in Biotechnology, 23, 510-515. https://doi.org/10.1016/j.copbio.2011.11. 032.

Francius, G., Alsteens, D., Dupres, V., Lebeer, S., De Keersmaecker, S., Vanderleyden, J. et al. (2009). Stretching polysaccharides on live cells using single molecule force spectroscopy. Nature Protocols, 4, 939-946. https://doi.org/10.1038/nprot.2009.65.

Francius, G., Lebeer, S., Alsteens, D., Wildling, L., Gruber, H. J., Hols, P., et al. (2008). 
Detection, localization, and conformational analysis of single polysaccharide molecules on live bacteria. ACS Nano, 2, 1921-1929. https://doi.org/10.1021/ nn800341b.

Franz, V., Loi, S., Müller, H., Bamberg, E., \& Butt, H.-J. (2002). Tip penetration through lipid bilayers in atomic force microscopy. Colloids and Surfaces B: Biointerfaces, 23, 191-200. https://doi.org/10.1016/S0927-7765(01)00254-5.

Freitas, C. D. T., Silva, M. Z. R., Oliveira, J. P. B., Silva, A. F. B., Ramos, M. V., \& de Sousa, J. S. (2019). Study of milk coagulation induced by chymosin using atomic force microscopy. Food Bioscience, 29, 81-85. https://doi.org/10.1016/j.fbio.2019.04.003.

Friedrichs, J., Legate, K. R., Schubert, R., Bharadwaj, M., Werner, C., Müller, D. J., et al. (2013). A practical guide to quantify cell adhesion using single-cell force spectroscopy. Methods, 60, 169-178. https://doi.org/10.1016/j.ymeth.2013.01.006.

Fukuda, S., Uchihashi, T., Iino, R., Okazaki, Y., Yoshida, M., Igarashi, K., et al. (2013). High-speed atomic force microscope combined with single-molecule fluorescence microscope. Review of Scientific Instruments, 84, 073706. https://doi.org/10.1063/1. 4813280.

Funami, T. (2010). Atomic force microscopy imaging of food polysaccharides. Food Science and Technology Research, 16, 1-12. https://doi.org/10.3136/fstr.16.1.

Gallier, S., Gragson, D., Jiménez-Flores, R., \& Everett, D. W. (2010). Surface characterization of bovine milk phospholipid monolayers by Langmuir isotherms and microscopic techniques. Journal of Agricultural and Food Chemistry, 58, 12275-12285. https://doi.org/10.1021/jf102185a.

Galus, S., \& Kadzińska, J. (2016). Whey protein edible films modified with almond and walnut oils. Food Hydrocolloids, 52, 78-86. https://doi.org/10.1016/j.foodhyd.2015. 06.013.

Gao, Y., Wang, J., Zhong, J., Wang, Y., Yin, Q., Hou, B., et al. (2017). Application of atomic force microscopy in understanding crystallization process. Science of Advanced Materials, 9, 89-101. https://doi.org/10.1166/sam.2017.2765.

García-Arribas, A. B., Busto, J. V., Alonso, A., \& Goñi, F. M. (2015). Atomic force microscopy characterization of palmitoylceramide and cholesterol effects on phospholipid bilayers: A topographic and nanomechanical study. Langmuir, 31, 3135-3145. https://doi.org/10.1021/la504047n.

Garcia-Manyes, S., Oncins, G., \& Sanz, F. (2005). Effect of temperature on the nanomechanics of lipid bilayers studied by force spectroscopy. Biophysical Journal, 89, 4261-4274. https://doi.org/10.1529/biophysj.105.065581.

Garcia-Manyes, S., \& Sanz, F. (2010). Nanomechanics of lipid bilayers by force spectroscopy with AFM: A perspective. Biochimica et Biophysica Acta (BBA) - Biomembranes, 1798, 741-749. https://doi.org/10.1016/j.bbamem.2009.12.019.

Gavara, N. (2017). A beginner's guide to atomic force microscopy probing for cell mechanics. Microscopy Research and Technique, 80, 75-84. https://doi.org/10.1002/ jemt. 22776.

Gebhardt, R., Doster, W., Friedrich, J., \& Kulozik, U. (2006). Size distribution of pressuredecomposed casein micelles studied by dynamic light scattering and AFM. European Biophysics Journal, 35, 503-509. https://doi.org/10.1007/s00249-006-0058-6.

Gebhardt, R., Holzmüller, W., Zhong, Q., Müller-Buschbaum, P., \& Kulozik, U. (2011). Structural ordering of casein micelles on silicon nitride micro-sieves during filtration. Colloids and Surfaces B: Biointerfaces, 88, 240-245. https://doi.org/10.1016/j. colsurfb.2011.06.038.

Giocondi, M.-C., Besson, F., Dosset, P., Milhiet, P.-E., \& Le Grimellec, C. (2007). Remodeling of ordered membrane domains by GPI-anchored intestinal alkaline phosphatase. Langmuir, 23, 9358-9364. https://doi.org/10.1021/la700892z.

Giocondi, M.-C., Yamamoto, D., Lesniewska, E., Milhiet, P.-E., Ando, T., \& Le Grimellec, C. (2010). Surface topography of membrane domains. Biochimica et Biophysica Acta (BBA) - Biomembranes, 1798, 703-718. https://doi.org/10.1016/j.bbamem.2009.09. 015.

Golovko, D. S., Bonanno, P., Lorenzoni, S., Stefani, F., Raiteri, R., \& Bonaccurso, E. (2008). Evaporative cooling of sessile water microdrops measured with atomic force microscope cantilevers. Journal of Micromechanics and Microengineering, 18, 095026. https://doi.org/10.1088/0960-1317/18/9/095026.

Gomand, F., Borges, F., Guerin, J., El-Kirat-Chatel, S., Francius, G., Dumas, D., et al. (2019). Adhesive interactions between lactic acid bacteria and $\beta$-lactoglobulin: Specificity and impact on bacterial location in whey protein isolate. Frontiers in Microbiology, 10, 1512. https://doi.org/10.3389/fmicb.2019.01512.

Gosal, W. S., Clark, A. H., \& Ross-Murphy, S. B. (2004). Fibrillar $\beta$-lactoglobulin gels: Part 1. Fibril formation and structure. Biomacromolecules, 5, 2408-2419. https://doi.org/ 10.1021/bm049659d.

Grant, C. A., McKendry, J. E., \& Evans, S. D. (2012). Temperature dependent stiffness and visco-elastic behaviour of lipid coated microbubbles using atomic force microscopy. Soft Matter, 8, 1321-1326. https://doi.org/10.1039/C1SM06578E.

Gromer, A., Penfold, R., Gunning, A. P., Kirby, A. R., \& Morris, V. J. (2010). Molecular basis for the emulsifying properties of sugar beet pectin studied by atomic force microscopy and force spectroscopy. Soft Matter, 6, 3957-3969. https://doi.org/10. 1039/c0sm00089b.

Gucht, J. van der, Spruijt, E., Lemmers, M., \& Cohen Stuart, M. A. (2011). Polyelectrolyte complexes: Bulk phases and colloidal systems. Journal of Colloid and Interface Science, 361, 407-422. https://doi.org/10.1016/j.jcis.2011.05.080.

Guerin, J., Bacharouche, J., Burgain, J., Lebeer, S., Francius, G., Borges, F., et al. (2016). Pili of Lactobacillus rhamnosus GG mediate interaction with $\beta$-lactoglobulin. Food Hydrocolloids, 58, 35-41. https://doi.org/10.1016/j.foodhyd.2016.02.016.

Guerin, J., Soligot, C., Burgain, J., Huguet, M., Francius, G., El-Kirat-Chatel, S., et al. (2018). Adhesive interactions between milk fat globule membrane and Lactobacillus rhamnosus GG inhibit bacterial attachment to Caco-2 TC7 intestinal cell. Colloids and Surfaces B: Biointerfaces, 167, 44-53. https://doi.org/10.1016/j.colsurfb.2018.03. 044.

Gumí-Audenis, B., Carlà, F., Vitorino, M. V., Panzarella, A., Porcar, L., Boilot, M., et al. (2015). Custom AFM for X-ray beamlines: In situ biological investigations under physiological conditions. Journal of Synchrotron Radiation, 22, 1364-1371. https:// doi.org/10.1107/S1600577515016318.

Gunning, A. P., Kirby, A. R., Wilde, P. J., Penfold, R., Woodward, N. C., \& Morris, V. J. (2013). Probing the role of interfacial rheology in the relaxation behaviour between deformable oil droplets using force spectroscopy. Soft Matter, 9, 11473-11479. https://doi.org/10.1039/c3sm52341a.

Gunning, A. P., Mackie, A. R., Wilde, P. J., \& Morris, V. J. (2004). Atomic force microscopy of emulsion droplets: Probing droplet-droplet interactions. Langmuir, 20, 116-122. https://doi.org/10.1021/la034835.

Gunning, A. P., \& Morris, V. J. (2018). Getting the feel of food structure with atomic force microscopy. Food Hydrocolloids, 78, 62-76. https://doi.org/10.1016/j.foodhyd.2017. 05.017.

Guo, Q., Ye, A., Bellissimo, N., Singh, H., \& Rousseau, D. (2017). Modulating fat digestion through food structure design. Progress in Lipid Research, 68, 109-118. https://doi. org/10.1016/j.plipres.2017.10.001.

Guyomarc'h, F., Chen, M., Et-Thakafy, O., Zou, S., \& Lopez, C. (2017). Gel-gel phase separation within milk sphingomyelin domains revealed at the nanoscale using atomic force microscopy. Biochimica et Biophysica Acta (BBA) - Biomembranes, 1859, 949-958. https://doi.org/10.1016/j.bbamem.2017.02.010.

Guyomarc'h, F., Zou, S., Chen, M., Milhiet, P.-E., Godefroy, C., Vié, V., et al. (2014). Milk sphingomyelin domains in biomimetic membranes and the role of cholesterol: Morphology and nanomechanical properties investigated using AFM and force spectroscopy. Langmuir, 30, 6516-6524. https://doi.org/10.1021/la501640y.

Haschke, T., Lautenschlager, D., Wiechert, W., Bonaccurso, E., \& Butt, J. (2005). Simulation of evaporating droplets on AFM-cantilevers. Proceedings of the COMSOL multiphysics user's conference. Frankfurt, Germany, 2005 https://www.researchgate. net/publication/265926323_Simulation_of_Evaporating_Droplets_on_AFMCantilevers.

Heinz, W. F., \& Hoh, J. H. (1999). Spatially resolved force spectroscopy of biological surfaces using the atomic force microscope. Trends in Biotechnology, 17, 143-150. https://doi.org/10.1016/S0167-7799(99)01304-9.

Helstad, K., Rayner, M., van Vliet, T., Paulsson, M., \& Dejmek, P. (2007). Liquid dropletlike behaviour of whole casein aggregates adsorbed on graphite studied by nanoindentation with AFM. Food Hydrocolloids, 21, 726-738. https://doi.org/10.1016/ j.foodhyd.2006.10.006.

Hodge, S. M., \& Rousseau, D. (2002). Fat bloom formation and characterization in milk chocolate observed by atomic force microscopy. Journal of the American Oil Chemists' Society, 79, 1115-1121. https://doi.org/10.1007/s11746-002-0613-4.

Hu, J., Yang, J., Xu, Y., Zhang, K., Nishinari, K., Phillips, G. O., et al. (2019). Comparative study on foaming and emulsifying properties of different beta-lactoglobulin aggregates. Food \& Function, 10, 5922-5930. https://doi.org/10.1039/C9FO00940J.

Ikeda, S., Funami, T., \& Zhang, G. (2005). Visualizing surface active hydrocolloids by atomic force microscopy. Carbohydrate Polymers, 62, 192-196. https://doi.org/10. 1016/j.carbpol.2005.07.020.

Ikeda, S., \& Morris, V. J. (2002). Fine-stranded and particulate aggregates of heat-denatured whey proteins visualized by atomic force microscopy. Biomacromolecules, 3 , 382-389. https://doi.org/10.1021/bm0156429.

Jacquot, A., Francius, G., Razafitianamaharavo, A., Dehghani, F., Tamayol, A., Linder, M., et al. (2014). Morphological and physical analysis of natural phospholipids-based biomembranes. PloS One, 9, e107435. https://doi.org/10.1371/journal.pone. 0107435.

Janel, S., Werkmeister, E., Bongiovanni, A., Lafont, F., \& Barois, N. (2017). Clafem: Correlative light atomic force electron microscopy. In T. Müller-Reichert, \& P. Verkade (Vol. Eds.), Methods in cell biology: Vol. 140, (pp. 165-185). Cambridge, MA, USA: Academic Press. https://doi.org/10.1016/bs.mcb.2017.03.010.

Ji, B., Kenaan, A., Gao, S., Cheng, J., Cui, D., Yang, H., et al. (2019). Label-free detection of biotoxins via a photo-induced force infrared spectrum at the single-molecular level. The Analyst, 144, 6108-6117. https://doi.org/10.1039/C9AN01338E.

Jin, A. J., Lafer, E. M., Peng, J. Q., Smith, P. D., \& Nossal, R. (2013). Unraveling protein-protein interactions in clathrin assemblies via atomic force spectroscopy. Methods, 59, 316-327. https://doi.org/10.1016/j.ymeth.2012.12.006.

Johnson, M. P., Vasilev, C., Olsen, J. D., \& Hunter, C. N. (2014). Nanodomains of cytochrome b6f and photosystem II complexes in spinach grana thylakoid membranes. The Plant Cell Online, 26, 3051-3061. https://doi.org/10.1105/tpc.114.127233.

Jones, O. W. (2016). Developments in dynamic atomic force microscopy techniques to characterize viscoelastic behaviors of food materials at the nanometer-scale. Current Opinion in Food Science, 9, 77-83. https://doi.org/10.1016/j.cofs.2016.09.008.

Jones, O. G., Adamcik, J., Handschin, S., Bolisetty, S., \& Mezzenga, R. (2010). Fibrillation of $\beta$-lactoglobulin at low $\mathrm{pH}$ in the presence of a complexing anionic polysaccharide. Langmuir, 26, 17449-17458. https://doi.org/10.1021/la1026619.

Kainz, B., Oprzeska-Zingrebe, E. A., \& Herrera, J. L. (2014). Biomaterial and cellular properties as examined through atomic force microscopy, fluorescence optical microscopies and spectroscopic techniques. Biotechnology Journal, 9, 51-60. https://doi. org/10.1002/biot.201300087.

Kasas, S., Stupar, P., \& Dietler, G. (2018). AFM contribution to unveil pro- and eukaryotic cell mechanical properties. Seminars in Cell \& Developmental Biology, 73, 177-187. https://doi.org/10.1016/j.semcdb.2017.08.032.

Kloek, W., Van Vliet, T., \& Walstra, P. (2005). Large deformation behavior of fat crystal networks. Journal of Texture Studies, 36, 516-543. https://doi.org/10.1111/j.17454603.2005.00030.x.

Kurland, N. E., Drira, Z., \& Yadavalli, V. K. (2012). Measurement of nanomechanical properties of biomolecules using atomic force microscopy. Micron, 43, 116-128. https://doi.org/10.1016/j.micron.2011.07.017.

Lam, C. W. Y., \& Ikeda, S. (2017). The Young's modulus, fracture stress, and fracture strain of gellan hydrogels filled with whey protein microparticles. Journal of Food Science, 82, 1157-1162. https://doi.org/10.1111/1750-3841.13714. 
Lee, M., Kim, B., Kim, Q., Hwang, J., An, S., \& Jhe, W. (2016). Viscometry of single nanoliter-volume droplets using dynamic force spectroscopy. Physical Chemistry Chemical Physics, 18, 27684-27690. https://doi.org/10.1039/C6CP05896E.

Le, D. T. L., Guerardel, Y., Loubiere, P., Mercier-Bonin, M., \& Dague, E. (2011). Measuring kinetic dissociation/association constants between Lactococcus lactis bacteria and mucins using living cell probes. Biophysical Journal, 101, 2843-2853. https://doi.org/ 10.1016/j.bpj.2011.10.034.

Lekka, M., Sainz-Serp, D., Kulik, A. J., \& Wandrey, C. (2004). Hydrogel microspheres: Influence of chemical composition on surface morphology, local elastic properties, and bulk mechanical characteristics. Langmuir, 20, 9968-9977. https://doi.org/10. 1021/la048389h.

Lemaire, E., Heinisch, M., Caillard, B., Jakoby, B., \& Dufour, I. (2013). Comparison and experimental validation of two potential resonant viscosity sensors in the kiloHertz range. Measurement Science and Technology, 24, 084005. https://doi.org/10.1088/ 0957-0233/24/8/084005.

Leonenko, Z. V., Finot, E., Ma, H., Dahms, T. E. S., \& Cramb, D. T. (2004). Investigation of temperature-induced phase transitions in DOPC and DPPC phospholipid bilayers using temperature-controlled scanning force microscopy. Biophysical Journal, 86, 3783-3793. https://doi.org/10.1529/biophysj.103.036681.

Li, T.-D., Chiu, H.-C., Ortiz-Young, D., \& Riedo, E. (2014). Nanorheology by atomic force microscopy. Review of Scientific Instruments, 85, 123707. https://doi.org/10.1063/1. 4903353.

Li, M., Wang, L., Zhang, W., Putnis, C. V., \& Putnis, A. (2016). Direct observation of spiral growth, particle attachment, and morphology evolution of hydroxyapatite. Crystal Growth \& Design, 16, 4509-4518. https://doi.org/10.1021/acs.cgd.6b00637.

Li, M., Wang, L., \& Putnis, C. V. (2018). Atomic force microscopy imaging of classical and nonclassical surface growth dynamics of calcium orthophosphates. CrystEngComm, 20, 2886-2896. https://doi.org/10.1039/C7CE02100C.

Liang, X., Mao, G., \& Ng, K. Y. S. (2004). Mechanical properties and stability measurement of cholesterol-containing liposome on mica by atomic force microscopy. Journal of Colloid and Interface Science, 278, 53-62. https://doi.org/10.1016/j.jcis.2004.05. 042.

Lin, M., Tay, S. H., Yang, H., Yang, B., \& Li, H. (2017). Development of eggless cakes suitable for lacto-vegetarians using isolated pea proteins. Food Hydrocolloids, 69 440-449. https://doi.org/10.1016/j.foodhyd.2017.03.014.

Liu, H., Qiao, H., Krajcikova, D., Zhang, Z., Wang, H., Barak, I., et al. (2016). Physical interaction and assembly of Bacillus subtilis spore coat proteins CotE and CotZ studied by atomic force microscopy. Journal of Structural Biology, 195, 245-251. https://doi. org/10.1016/j.jsb.2016.06.010.

Liu, S., \& Wang, Y. (2011). A review of the application of atomic force microscopy (AFM) in food science and technology. In S. L. Taylor (Vol. Ed.), Advances in food and nutrition research: Vol. 62, (pp. 201-240). Waltham, MA, USA: Academic Press. https:// doi.org/10.1016/B978-0-12-385989-1.00006-5.

Liu, Q., \& Yang, H. (2019). Application of atomic force microscopy in food microorganisms. Trends in Food Science \& Technology, 87, 73-83. https://doi.org/10.1016/j.tifs. 2018.05.010.

Lopez, C. (2011). Milk fat globules enveloped by their biological membrane: Unique colloidal assemblies with a specific composition and structure. Current Opinion in Colloid \& Interface Science, 16, 391-404. https://doi.org/10.1016/j.cocis.2011.05. 007.

Lopez, C., Cauty, C., \& Guyomarc'h, F. (2015). Organization of lipids in milks, infant milk formulas and various dairy products: Role of technological processes and potential impacts. Dairy Science \& Technology, 95, 863-893. https://doi.org/10.1007/s13594 015-0263-0.

Lubarsky, G. V., Davidson, M. R., \& Bradley, R. H. (2007). Hydration-dehydration of adsorbed protein films studied by AFM and QCM-D. Biosensors and Bioelectronics, 22, 1275-1281. https://doi.org/10.1016/j.bios.2006.05.024.

Lucero Caro, A., Rodríguez Niño, M. R., \& Rodríguez Patino, J. M. (2009). Topography of dipalmitoyl-phosphatidyl-choline monolayers penetrated by $\beta$-casein. Colloids and Surfaces A: Physicochemical and Engineering Aspects, 346, 146-157. https://doi.org/ 10.1016/j.colsurfa.2009.06.007.

Mackie, A. R., Gunning, A. P., Wilde, P. J., \& Morris, V. J. (1999). Orogenic displacement of protein from the air/water interface by competitive adsorption. Journal of Colloid and Interface Science, 210, 157-166. https://doi.org/10.1006/jcis.1998.5941.

Mackie, A. R., Gunning, A. P., Wilde, P. J., \& Morris, V. J. (2000). Orogenic displacement of protein from the oil/water interface. Langmuir, 16, 2242-2247. https://doi.org/10. 1021/la990711e.

Maldonado-Valderrama, J., Gunning, A. P., Wilde, P. J., \& Morris, V. J. (2010). In vitro gastric digestion of interfacial protein structures: Visualisation by AFM. Soft Matter, 6, 4908-4915. https://doi.org/10.1039/c0sm00300j.

Manibog, K., Yen, C. F., \& Sivasankar, S. (2017). Measuring force-induced dissociation kinetics of protein complexes using single-molecule atomic force microscopy. In A. M. Pyle, \& D. W. Christianson (Vol. Eds.), Methods in enzymology: Vol. 582, (pp. 297320). Cambridge, MA, USA: Academic Press. https://doi.org/10.1016/bs.mie.2016. 08.009 .

Manor, O., Chau, T. T., Stevens, G. W., Chan, D. Y. C., Grieser, F., \& Dagastine, R. R. (2012). Polymeric stabilized emulsions: Steric effects and deformation in soft systems. Langmuir, 28, 4599-4604. https://doi.org/10.1021/la204272u.

Marinello, F., La Storia, A., Mauriello, G., \& Passeri, D. (2019). Atomic force microscopy techniques to investigate activated food packaging materials. Trends in Food Science \& Technology, 87, 84-93. https://doi.org/10.1016/j.tifs.2018.05.028.

Marszalek, P. E., \& Dufrêne, Y. F. (2012). Stretching single polysaccharides and proteins using atomic force microscopy. Chemical Society Reviews, 41, 3523-3534. https://doi. org/10.1039/c2cs15329g.

Martinet, V., Saulnier, P., Beaumal, V., Courthaudon, J.-L., \& Anton, M. (2003). Surface properties of hen egg yolk low-density lipoproteins spread at the air-water interface.
Colloids and Surfaces B: Biointerfaces, 31, 185-194. https://doi.org/10.1016/S09277765(03)00139-5.

Marze, S. (2013). Bioaccessibility of nutrients and micronutrients from dispersed food systems: Impact of the multiscale bulk and interfacial structures. Critical Reviews in Food Science and Nutrition, 53, 76-108. https://doi.org/10.1080/10408398.2010. 525331.

Masterson, V. M., \& Cao, X. (2008). Evaluating particle hardness of pharmaceutical solids using AFM nanoindentation. International Journal of Pharmaceutics, 362, 163-171. https://doi.org/10.1016/j.ijpharm.2008.06.015.

McGuiggan, P. M., \& Wallace, J. S. (2006). Maximum force technique for the measurement of the surface tension of a small droplet by AFM. The Journal of Adhesion, 82, 997-1011. https://doi.org/10.1080/00218460600876225.

Meagher, L., \& Griesser, H. J. (2002). Interactions between adsorbed lactoferrin layers measured directly with the atomic force microscope. Colloids and Surfaces B: Biointerfaces, 23, 125-140. https://doi.org/10.1016/S0927-7765(01)00234-X.

Mellema, M., van Opheusden, J. H. J., \& van Vliet, T. (2002). Categorization of rheological scaling models for particle gels applied to casein gels. Journal of Rheology, 46, 11-29. https://doi.org/10.1122/1.1423311.

Mettu, S., Wu, C., \& Dagastine, R. R. (2018). Dynamic forces between emulsified water drops coated with poly-glycerol-poly-ricinoleate (PGPR) in canola oil. Journal of Colloid and Interface Science, 517, 166-175. https://doi.org/10.1016/j.jcis.2018.01. 104.

Middendorf, D., Bindrich, U., Mischnick, P., Franke, K., \& Heinz, V. (2018). AFM-based local thermal analysis is a suitable tool to characterize the impact of different grinding techniques on sucrose surface properties. Journal of Food Engineering, 235, 50-58. https://doi.org/10.1016/j.jfoodeng.2018.04.021.

Middendorf, D., Bindrich, U., Mischnick, P., Juadjur, A., Franke, K., \& Heinz, V. (2016) Atomic force microscopy study on the effect of different lecithins in cocoa-butter based suspensions. Colloids and Surfaces A: Physicochemical and Engineering Aspects, 499, 60-68. https://doi.org/10.1016/j.colsurfa.2016.03.057.

Monchaux, E., \& Vermette, P. (2007). Development of dextran-derivative arrays to identify physicochemical properties involved in biofouling from serum. Langmuir, 23, 3290-3297. https://doi.org/10.1021/la063012s.

Morandat, S., Azouzi, S., Beauvais, E., Mastouri, A., \& El Kirat, K. (2013). Atomic force microscopy of model lipid membranes. Analytical and Bioanalytical Chemistry, 405, 1445-1461. https://doi.org/10.1007/s00216-012-6383-y.

Morris, V. J. (2004). Probing molecular interactions in foods. Trends in Food Science \& Technology, 15, 291-297. https://doi.org/10.1016/j.tifs.2003.04.001.

Moschakis, T., \& Biliaderis, C. G. (2017). Biopolymer-based coacervates: Structures, functionality and applications in food products. Current Opinion in Colloid \& Interface Science, 28, 96-109. https://doi.org/10.1016/j.cocis.2017.03.006.

Müller, D. J., Krieg, M., Alsteens, D., \& Dufrêne, Y. F. (2009). New frontiers in atomic force microscopy: Analyzing interactions from single-molecules to cells. Current Opinion in Biotechnology, 20, 4-13. https://doi.org/10.1016/j.copbio.2009.02.005.

Munz, M., \& Mills, T. (2014). Size dependence of shape and stiffness of single sessile oil nanodroplets as measured by atomic force microscopy. Langmuir, 30, 4243-4252. https://doi.org/10.1021/la5001446.

Murrieta-Pazos, I., Gaiani, C., Galet, L., Calvet, R., Cuq, B., \& Scher, J. (2012). Food powders: Surface and form characterization revisited. Journal of Food Engineering, 112, 1-21. https://doi.org/10.1016/j.jfoodeng.2012.03.002.

Murthy, A. V. R., Guyomarc'h, F., \& Lopez, C. (2016a). The temperature-dependent physical state of polar lipids and their miscibility impact the topography and mechanical properties of bilayer models of the milk fat globule membrane. Biochimica et Biophysica Acta (BBA) - Biomembranes, 1858, 2181-2190. https://doi.org/10.1016/j. bbamem.2016.06.020.

Murthy, A. V. R., Guyomarc'h, F., \& Lopez, C. (2016b). Cholesterol decreases the size and the mechanical resistance to rupture of sphingomyelin rich domains, in lipid bilayers studied as a model of the milk fat globule membrane. Langmuir, 32, 6757-6765 https://doi.org/10.1021/acs.langmuir.6b01040.

Nagy, K., Váró, G., \& Szalontai, B. (2012). $\kappa$-Casein terminates casein micelle build-up by its "soft" secondary structure. European Biophysics Journal, 41, 959-968. https://doi org/10.1007/s00249-012-0854-0.

Najbar, L. V., Considine, R. F., \& Drummond, C. J. (2003). Heat-induced aggregation of a globular egg-white protein in aqueous solution: Investigation by atomic force microscope imaging and surface force mapping modalities. Langmuir, 19, 2880-2887. https://doi.org/10.1021/la0263108.

Nigen, M., Gaillard, C., Croguennec, T., Madec, M.-N., \& Bouhallab, S. (2010). Dynamic and supramolecular organisation of $\alpha$-lactalbumin/lysozyme microspheres: A microscopic study. Biophysical Chemistry, 146, 30-35. https://doi.org/10.1016/j.bpc. 2009.10.001.

Nowak, K. W., Markowski, M., \& Daszkiewicz, T. (2015). Ultrasonic determination of mechanical properties of meat products. Journal of Food Engineering, 147, 49-55. https://doi.org/10.1016/j.jfoodeng.2014.09.024.

Obeid, S., Guyomarc'h, F., David-Briand, E., Gaucheron, F., Riaublanc, A., \& Lopez, C. (2019b). The phase and charge of milk polar lipid membrane bilayers govern their selective interactions with proteins as demonstrated with casein micelles. Journal of Colloid and Interface Science, 534, 279-290. https://doi.org/10.1016/j.jcis.2018.09. 033.

Obeid, S., Guyomarc'h, F., Francius, G., Guillemin, H., Wu, X., Pezennec, S., et al. (2019a). The surface properties of milk fat globules govern their interactions with the caseins: Role of homogenization and $\mathrm{pH}$ probed by AFM force spectroscopy. Colloids and Surfaces B: Biointerfaces, 182, 110363. https://doi.org/10.1016/j.colsurfb.2019. 110363.

Obeid, S., Guyomarc'h, F., Tanguy, G., Leconte, N., Rousseau, F., Dolivet, A., et al. (2020). The adhesion of homogenized fat globules to proteins is increased by milk heat treatment and acidic pH: Quantitative insights provided by AFM force spectroscopy. 
Food Research International, 129, 108847. https://doi.org/10.1016/j.foodres.2019. 108847.

Olivares, M. L., Passeggi, M. C. G., Ferrón, J., Zorrilla, S. E., \& Rubiolo, A. C. (2010). Study of milk/к-carrageenan mixtures by atomic force microscopy. Food Hydrocolloids, 24, 776-782. https://doi.org/10.1016/j.foodhyd.2010.04.004.

Opilik, L., Bauer, T., Schmid, T., Stadler, J., \& Zenobi, R. (2011). Nanoscale chemical imaging of segregated lipid domains using tip-enhanced Raman spectroscopy. Physical Chemistry Chemical Physics, 13, 9978-9981. https://doi.org/10.1039/ c0cp02832k.

Ouanezar, M., Guyomarc'h, F., \& Bouchoux, A. (2012). AFM imaging of milk casein micelles: Evidence for structural rearrangement upon acidification. Langmuir, 28, 4915-4919. https://doi.org/10.1021/la3001448.

Paluszkiewicz, C., Piergies, N., Chaniecki, P., Rękas, M., Miszczyk, J., \& Kwiatek, W. M. (2017). Differentiation of protein secondary structure in clear and opaque human lenses: AFM - IR studies. Journal of Pharmaceutical and Biomedical Analysis, 139, 125-132. https://doi.org/10.1016/j.jpba.2017.03.001.

Pan, K., Chen, H., Davidson, P. M., \& Zhong, Q. (2014). Thymol nanoencapsulated by sodium caseinate: Physical and antilisterial properties. Journal of Agricultural and Food Chemistry, 62, 1649-1657. https://doi.org/10.1021/jf4055402.

Papi, M., Arcovito, G., De Spirito, M., Vassalli, M., \& Tiribilli, B. (2006). Fluid viscosity determination by means of uncalibrated atomic force microscopy cantilevers. Applied Physics Letters, 88, 194102. https://doi.org/10.1063/1.2200588.

Parot, P., Dufrêne, Y. F., Hinterdorfer, P., Le Grimellec, C., Navajas, D., Pellequer, J.-L., et al. (2007). Past, present and future of atomic force microscopy in life sciences and medicine. Journal of Molecular Recognition, 20, 418-431. https://doi.org/10.1002/ jmr.857.

Pasquier, C., Beaufils, S., Bouchoux, A., Rigault, S., Cabane, B., Lund, M., et al. (2016). Osmotic pressures of lysozyme solutions from gas-like to crystal states. Physical Chemistry Chemical Physics, 18, 28458-28465. https://doi.org/10.1039/ C6CP03867K.

de sa Peixoto, P., Roiland, C., Thomas, D., Briard-Bion, V., Le Guellec, R., Parayre, S., et al. (2015). Recrystallized S-layer protein of a probiotic Propionibacterium: Structural and nanomechanical changes upon temperature or $\mathrm{pH}$ shifts probed by solid-state NMR and AFM. Langmuir, 31, 199-208. https://doi.org/10.1021/ la503735z.

Pellequer, J.-L., Parot, P., Navajas, D., Kumar, S., Svetličić, V., Scheuring, S., et al. (2019). Fifteen years of Servitude et Grandeur to the application of a biophysical technique in medicine: The tale of AFMBioMed. Journal of Molecular Recognition, 32, e2773. https://doi.org/10.1002/jmr.2773.

Pérez-Fuentes, L., Drummond, C., Faraudo, J., \& Bastos-González, D. (2017). Adsorption of milk proteins ( $\beta$-casein and $\beta$-lactoglobulin) and BSA onto hydrophobic surfaces. Materials, 10, 893. https://doi.org/10.3390/ma10080893.

Perkins, M., Ebbens, S. J., Hayes, S., Roberts, C. J., Madden, C. E., Luk, S. Y., et al. (2007). Elastic modulus measurements from individual lactose particles using atomic force microscopy. International Journal of Pharmaceutics, 332, 168-175. https://doi.org/10. 1016/j.ijpharm.2006.09.032.

Picas, L., Rico, F., \& Scheuring, S. (2012). Direct measurement of the mechanical properties of lipid phases in supported bilayers. Biophysical Journal, 102, L01-L03. https://doi.org/10.1016/j.bpj.2011.11.4001.

Pillet, F., Lemonier, S., Schiavone, M., Formosa, C., Martin-Yken, H., Francois, J., et al. (2014). Uncovering by atomic force microscopy of an original circular structure at the yeast cell surface in response to heat shock. BMC Biology, 12, 6. https://doi.org/ 10.1186/1741-7007-12-6.

Posé, S., Paniagua, C., Matas, A. J., Gunning, A. P., Morris, V. J., Quesada, M. A., et al. (2019). A nanostructural view of the cell wall disassembly process during fruit ripening and postharvest storage by atomic force microscopy. Trends in Food Science \& Technology, 87, 47-58. https://doi.org/10.1016/j.tifs.2018.02.011.

Redondo-Morata, L., Giannotti, M. I., \& Sanz, F. (2012). AFM-based force-clamp monitors lipid bilayer failure kinetics. Langmuir, 28, 6403-6410. https://doi.org/10.1021/ la3005147.

Redondo-Morata, L., Giannotti, M. I., \& Sanz, F. (2014). Structural impact of cations on lipid bilayer models: Nanomechanical properties by AFM-force spectroscopy. Molecular Membrane Biology, 31, 17-28. https://doi.org/10.3109/09687688.2013. 868940.

Regnault, S., Thiebaud, M., Dumay, E., \& Cheftel, J. C. (2004). Pressurisation of raw skim milk and of a dispersion of phosphocaseinate at $9^{\circ} \mathrm{C}$ or $20^{\circ} \mathrm{C}$ : Effects on casein micelle size distribution. International Dairy Journal, 14, 55-68. https://doi.org/10.1016/ S0958-6946(03)00144-4.

Richard Bowen, W., Hilal, N., Lovitt, R. W., \& Wright, C. J. (1999). Characterisation of membrane surfaces: Direct measurement of biological adhesion using an atomic force microscope. Journal of Membrane Science, 154, 205-212. https://doi.org/10.1016/ S0376-7388(98)00287-7.

Rico, F., Rigato, A., Picas, L., \& Scheuring, S. (2013). Mechanics of proteins with a focus on atomic force microscopy. Journal of Nanobiotechnology, 11. https://doi.org/10. 1186/1477-3155-11-S1-S3 S3.

Rief, M. (1997). Reversible unfolding of individual titin immunoglobulin domains by AFM. Science, 276, 1109-1112. https://doi.org/10.1126/science.276.5315.1109.

te Riet, J., Reinieren-Beeren, I., Figdor, C. G., \& Cambi, A. (2015). AFM force spectroscopy reveals how subtle structural differences affect the interaction strength between Candida albicans and DC-SIGN: AFM force spectroscopy reveals recognition of $C$. albicans by DC-SIGN. Journal of Molecular Recognition, 28, 687-698. https://doi.org/10. 1002/jmr.2481.

Roesch, R., Cox, S., Compton, S., Happek, U., \& Corredig, M. (2004). к-Carrageenan and $\beta$-lactoglobulin interactions visualized by atomic force microscopy. Food Hydrocolloids, 18, 429-439. https://doi.org/10.1016/j.foodhyd.2003.08.001.

Roos, Y. H., Fryer, P. J., Knorr, D., Schuchmann, H. P., Schroën, K., Schutyser, M. A. I., et al. (2016). Food engineering at multiple scales: Case studies, challenges and the future - a European perspective. Food Engineering Reviews, 8, 91-115. https://doi. org/10.1007/s12393-015-9125-z.

Rousseau, D., \& Sonwai, S. (2008). Influence of the dispersed particulate in chocolate on cocoa butter microstructure and fat crystal growth during storage. Food Biophysics, 3, 273-278. https://doi.org/10.1007/s11483-008-9061-z.

Ruiz-Cabello, F. J. M., Trefalt, G., Csendes, Z., Sinha, P., Oncsik, T., Szilagyi, I., et al. (2013). Predicting aggregation rates of colloidal particles from direct force measurements. The Journal of Physical Chemistry B, 117, 11853-11862. https://doi.org/ 10.1021/jp406061f.

Sadek, C., Pauchard, L., Schuck, P., Fallourd, Y., Pradeau, N., Le Floch-Fouéré, C., et al. (2015). Mechanical properties of milk protein skin layers after drying: Understanding the mechanisms of particle formation from whey protein isolate and native phosphocaseinate. Food Hydrocolloids, 48, 8-16. https://doi.org/10.1016/j.foodhyd.2015. 01.014.

Sarrazin, B., Tsapis, N., Mousnier, L., Taulier, N., Urbach, W., \& Guenoun, P. (2016). AFM investigation of liquid-filled polymer microcapsules elasticity. Langmuir, 32, 4610-4618. https://doi.org/10.1021/acs.langmuir.6b00431.

Schaer-Zammaretti, P., \& Ubbink, J. (2003). Imaging of lactic acid bacteria with AFM elasticity and adhesion maps and their relationship to biological and structural data. Ultramicroscopy, 97, 199-208. https://doi.org/10.1016/S0304-3991(03)00044-5.

Senapati, S., \& Lindsay, S. (2016). Recent progress in molecular recognition imaging using atomic force microscopy. Accounts of Chemical Research, 49, 503-510. https:// doi.org/10.1021/acs.accounts.5b00533.

Shao, Z., Shi, D., \& Somlyo, A. V. (2000). Cryoatomic force microscopy of filamentous actin. Biophysical Journal, 78, 950-958. https://doi.org/10.1016/S0006-3495(00) $76652-5$.

Shao, Z., \& Zhang, Y. (1996). Biological cryo atomic force microscopy: A brief review. Ultramicroscopy, 66, 141-152. https://doi.org/10.1016/S0304-3991(96)00087-3.

Sheng, S., Gao, Y., Khromov, A. S., Somlyo, A. V., Somlyo, A. P., \& Shao, Z. (2003). Cryoatomic force microscopy of unphosphorylated and thiophosphorylated single smooth muscle myosin molecules. Journal of Biological Chemistry, 278, 39892-39896. https:// doi.org/10.1074/jbc.M306094200.

Shi, C., Bi, C., Ding, M., Xie, J., Xu, C., Qiao, R., et al. (2019a). Polymorphism and stability of nanostructures of three types of collagens from bovine flexor tendon, rat tail, and tilapia skin. Food Hydrocolloids, 93, 253-260. https://doi.org/10.1016/j.foodhyd. 2019.02.035.

Shi, C., He, Y., Ding, M., Wang, Y., \& Zhong, J. (2019b). Nanoimaging of food proteins by atomic force microscopy. Part I: Components, imaging modes, observation ways, and research types. Trends in Food Science \& Technology, 87, 3-13. https://doi.org/10. 1016/j.tifs.2018.11.028.

Shi, C., He, Y., Ding, M., Wang, Y., \& Zhong, J. (2019c). Nanoimaging of food proteins by atomic force microscopy. Part II: Application for food proteins from different sources. Trends in Food Science \& Technology, 87, 14-25. https://doi.org/10.1016/j.tifs.2018. 11.027.

Shim, J., Stewart, D. S., Nikolov, A. D., Wasan, D. T., Wang, R., Yan, R., et al. (2017). Differential MS2 interaction with food contact surfaces determined by atomic force microscopy and virus recovery. Applied and Environmental Microbiology, 83. https:// doi.org/10.1128/AEM.01881-17 e01881-17.

Silva, N. N., Bahri, A., Guyomarc'h, F., Beaucher, E., \& Gaucheron, F. (2015). AFM study of casein micelles cross-linked by genipin: Effects of acid $\mathrm{pH}$ and citrate. Dairy Science \& Technology, 95, 75-86. https://doi.org/10.1007/s13594-014-0199-9.

Singh, G., Bremmell, K. E., Griesser, H. J., \& Kingshott, P. (2015). Colloid-probe AFM studies of the interaction forces of proteins adsorbed on colloidal crystals. Soft Matter, 11, 3188-3197. https://doi.org/10.1039/C4SM02669A.

Sinha, P., Popa, I., Finessi, M., Ruiz-Cabello, F. J. M., Szilágyi, I., Maroni, P., et al. (2012). Exploring forces between individual colloidal particles with the atomic force microscope. CHIMIA International Journal for Chemistry, 66, 214-217. https://doi.org/ 10.2533/chimia.2012.214.

Smith, P. R., \& Dahlman, A. (2005). The use of atomic force microscopy to measure the formation and development of chocolate bloom in pralines. Journal of the American Oil Chemists' Society, 82, 165-168. https://doi.org/10.1007/s11746-005-5167-3.

Somnath, S., Jesse, S., Van Berkel, G. J., Kalinin, S. V., \& Ovchinnikova, O. S. (2016). Submicron spatial resolution in thermal desorption mass spectrometry via rapid heating functions using thermal AFM probes. Microscopy and Microanalysis, 22, 368-369. https://doi.org/10.1017/S1431927616002695.

Spruijt, E., Cohen Stuart, M. A., \& van der Gucht, J. (2010). Dynamic force spectroscopy of oppositely charged polyelectrolyte brushes. Macromolecules, 43, 1543-1550. https://doi.org/10.1021/ma902403a.

Sullan, R. M. A., Li, J. K., Hao, C., Walker, G. C., \& Zou, S. (2010). Cholesterol-dependent nanomechanical stability of phase-segregated multicomponent lipid bilayers. Biophysical Journal, 99, 507-516. https://doi.org/10.1016/j.bpj.2010.04.044.

Sullan, R. M. A., Li, J. K., \& Zou, S. (2009). Direct correlation of structures and nanomechanical properties of multicomponent lipid bilayers. Langmuir, 25, 7471-7477. https://doi.org/10.1021/la900395w.

Sweetenham, C. S., Larraona-Puy, M., \& Notingher, I. (2011). Simultaneous surface-enhanced Raman spectroscopy (SERS) and atomic force microscopy (AFM) for label-free physicochemical analysis of lipid bilayers. Applied Spectroscopy, 65, 1387-1392. https://doi.org/10.1366/11-06319.

Tabor, R. F., Grieser, F., Dagastine, R. R., \& Chan, D. Y. C. (2012). Measurement and analysis of forces in bubble and droplet systems using AFM. Journal of Colloid and Interface Science, 371, 1-14. https://doi.org/10.1016/j.jcis.2011.12.047.

Tabor, R. F., Lockie, H., Mair, D., Manica, R., Chan, D. Y. C., Grieser, F., et al. (2011). Combined AFM - confocal microscopy of oil droplets: Absolute separations and forces in nanofilms. Journal of Physical Chemistry Letters, 2, 961-965. https://doi.org/10. 1021/jz2003606. 
Takechi-Haraya, Y., Sakai-Kato, K., Abe, Y., Kawanishi, T., Okuda, H., \& Goda, Y. (2016). Atomic force microscopic analysis of the effect of lipid composition on liposome membrane rigidity. Langmuir, 32, 6074-6082. https://doi.org/10.1021/acs. langmuir.6b00741.

Tan, S., Mettu, S., Biviano, M. D., Zhou, M., Babgi, B., White, J., et al. (2016). Ultrasonic synthesis of stable oil filled microcapsules using thiolated chitosan and their characterization by AFM and numerical simulations. Soft Matter, 12, 7212-7222. https:// doi.org/10.1039/C6SM01402J.

Tanaka, H., \& Araki, T. (2007). Spontaneous coarsening of a colloidal network driven by self-generated mechanical stress. Europhysics Letters, 79, 58003. https://doi.org/10. 1209/0295-5075/79/58003.

Tang, C.-H., Wang, S.-S., \& Huang, Q. (2012). Improvement of heat-induced fibril assembly of soy $\beta$-conglycinin (7S globulins) at $\mathrm{pH} 2.0$ through electrostatic screening. Food Research International, 46, 229-236. https://doi.org/10.1016/j.foodres.2011.11. 030 .

Toca-Herrera, J. L., Moreno-Flores, S., Friedmann, J., Pum, D., \& Sleytr, U. B. (2004). Chemical and thermal denaturation of crystalline bacterial S-layer proteins: An atomic force microscopy study. Microscopy Research and Technique, 65, 226-234. https://doi.org/10.1002/jemt.20127.

Touhami, A., Alexander, M., Kurylowicz, M., Gram, C., Corredig, M., \& Dutcher, J. R. (2011). Probing protein conformations at the oil droplet-water interface using singlemolecule force spectroscopy. Soft Matter, 7, 10274-10284. https://doi.org/10.1039/ c1sm06284k.

Touhami, A., \& Dutcher, J. R. (2009). pH-induced changes in adsorbed $\beta$-lactoglobulin molecules measured using atomic force microscopy. Soft Matter, 5, 220-227. https:// doi.org/10.1039/b811609a.

Touhami, A., Jericho, M. H., \& Beveridge, T. J. (2007). Molecular recognition forces between immunoglobulin G and a surface protein adhesin on living Staphylococcus aureus. Langmuir, 23, 2755-2760. https://doi.org/10.1021/la0628930.

Touhami, A., Jericho, M. H., Boyd, J. M., \& Beveridge, T. J. (2006). Nanoscale characterization and determination of adhesion forces of Pseudomonas aeruginosa pili by using atomic force microscopy. Journal of Bacteriology, 188, 370-377. https://doi. org /10.1128/JB.188.2.370-377.2006.

Touhami, A., Nysten, B., \& Dufrene, Y. F. (2003). Nanoscale mapping of the elasticity of microbial cells by atomic force microscopy. Langmuir, 19, 4539-4543. https://doi. org/10.1021/la034136x.

Treffer, R., Böhme, R., Deckert-Gaudig, T., Lau, K., Tiede, S., Lin, X., et al. (2012). Advances in TERS (tip-enhanced Raman scattering) for biochemical applications. Biochemical Society Transactions, 40, 609-614. https://doi.org/10.1042/ BST20120033.

Tskhovrebova, L., Trinick, J., Sleep, J. A., \& Simmons, R. M. (1997). Elasticity and unfolding of single molecules of the giant muscle protein titin. Nature, 387, 308-312. https://doi.org/10.1038/387308a0

Tytgat, H. L. P., van Teijlingen, N. H., Sullan, R. M. A., Douillard, F. P., Rasinkangas, P., Messing, M., et al. (2016). Probiotic gut microbiota isolate interacts with dendritic cells via glycosylated heterotrimeric pili. PloS One, 11, e0151824. https://doi.org/10. 1371/journal.pone. 0151824

Uchihashi, T., \& Scheuring, S. (2018). Applications of high-speed atomic force microscopy to real-time visualization of dynamic biomolecular processes. Biochimica et Biophysica Acta (BBA) - General Subjects, 229-240. https://doi.org/10.1016/j.bbagen.2017.07. 0101862.

Uddin, M. H., Tan, S. Y., \& Dagastine, R. R. (2011). Novel characterization of microdrops and microbubbles in emulsions and foams using atomic force microscopy. Langmuir, 27, 2536-2544. https://doi.org/10.1021/la104458z.

Uricanu, V. I., Duits, M. H. G., \& Mellema, J. (2004). Hierarchical networks of casein proteins: An elasticity study based on atomic force microscopy. Langmuir, 20, 5079-5090. https://doi.org/10.1021/la0363736.

Uricanu, V. I., Duits, M. H. G., Nelissen, R. M. F., Bennink, M. L., \& Mellema, J. (2003). Local structure and elasticity of soft gelatin gels studied with atomic force microscopy. Langmuir, 19, 8182-8194. https://doi.org/10.1021/la0347004.

Valle-Delgado, J. J., Molina-Bolívar, J. A., Galisteo-González, F., Gálvez-Ruiz, M. J., Feiler, A., \& Rutland, M. W. (2004). Interaction forces between BSA layers adsorbed on silica surfaces measured with an atomic force microscope. The Journal of Physical Chemistry B, 108, 5365-5371. https://doi.org/10.1021/jp0374197.

Valle-Delgado, J. J., Molina-Bolívar, J. A., Galisteo-González, F., Gálvez-Ruiz, M. J., Feiler, A., \& Rutland, M. W. (2005). Existence of hydration forces in the interaction between apoferritin molecules adsorbed on silica surfaces. Langmuir, 21, 9544-9554. https://doi.org/10.1021/la050825s.

Valle-Delgado, J. J., Molina-Bolívar, J. A., Galisteo-González, F., Gálvez-Ruiz, M. J., Feiler, A., \& Rutland, M. W. (2006). Adhesion forces between protein layers studied by means of atomic force microscopy. Langmuir, 22, 5108-5114. https://doi.org/10. 1021/la053011k.

Veatch, S. L. (2007). From small fluctuations to large-scale phase separation: Lateral organization in model membranes containing cholesterol. Seminars in Cell \& Developmental Biology, 18, 573-582. https://doi.org/10.1016/j.semcdb.2007.08.016.

Vithanage, C. R., Grimson, M. J., \& Smith, B. G. (2009). The effect of temperature on the rheology of butter, a spreadable blend and spreads. Journal of Texture Studies, 40, 346-369. https://doi.org/10.1111/j.1745-4603.2009.00186.x.

de Vries, M. S. (2015). AFM-MS achieves sub-micron spatial resolution. TRAC Trends in Analytical Chemistry, 66 (VII-VII).

Wackerbarth, H., Schön, P., \& Bindrich, U. (2009). Preparation and characterization of multilayer coated microdroplets: Droplet deformation simultaneously probed by atomic force spectroscopy and optical detection. Langmuir, 25, 2636-2640. https:// doi.org/10.1021/la802898k.

Walstra, P. (2002). Chapter 17: Soft solids. In P. Walstra (Ed.). Physical chemistry of foods (pp. 683-771). New York, NY, USA: Marcel Dekker Inc.

Wang, W., Li, K., Ma, M., Jin, H., Angeli, P., \& Gong, J. (2015). Review and perspectives of AFM application on the study of deformable drop/bubble interactions. Advances in Colloid and Interface Science, 225, 88-97. https://doi.org/10.1016/j.cis.2015.08.005.

Wang, L., Lu, J., Xu, F., \& Zhang, F. (2011). Dynamics of crystallization and dissolution of calcium orthophosphates at the near-molecular level. Chinese Science Bulletin, 56, 713-721. https://doi.org/10.1007/s11434-010-4184-2.

Wang, J., \& Nie, S. (2019). Application of atomic force microscopy in microscopic analysis of polysaccharide. Trends in Food Science \& Technology, 87, 35-46. https://doi. org/10.1016/j.tifs.2018.02.005.

Wang, T., Shogomori, H., Hara, M., Yamada, T., \& Kobayashi, T. (2012). Nanomechanical recognition of sphingomyelin-rich membrane domains by atomic force microscopy. Biochemistry, 51, 74-82. https://doi.org/10.1021/bi2011652.

Wang, J., \& Somasundaran, P. (2007). Study of galactomannose interaction with solids using AFM, IR and allied techniques. Journal of Colloid and Interface Science, 309, 373-383. https://doi.org/10.1016/j.jcis.2006.10.086.

Wang, S., Wang, X., Zhao, B., Wang, L., Qiu, J., Zhou, L., et al. (2016). Size-dependent stiffness of nanodroplets: A quantitative analysis of the interaction between an AFM probe and nanodroplets. Langmuir, 32, 11230-11235. https://doi.org/10.1021/acs. langmuir.6b01664.

Wei, Z., Cheng, J., \& Huang, Q. (2019). Food-grade Pickering emulsions stabilized by ovotransferrin fibrils. Food Hydrocolloids, 94, 592-602. https://doi.org/10.1016/j. foodhyd.2019.04.005.

Wei, Z., \& Huang, Q. (2020). In vitro digestion and stability under environmental stresses of ovotransferrin nanofibrils. Food Hydrocolloids, 99, 105343. https://doi.org/10. 1016/j.foodhyd.2019.105343.

Wei, H., \& van de Ven, T. G. M. (2008). AFM-based single molecule force spectroscopy of polymer chains: Theoretical models and applications. Applied Spectroscopy Reviews, 43, 111-133. https://doi.org/10.1080/05704920701831254.

Withers, J. R., \& Aston, D. E. (2006). Nanomechanical measurements with AFM in the elastic limit. Advances in Colloid and Interface Science, 120, 57-67. https://doi.org/10. 1016/j.cis.2006.03.002

Woodward, N. C., Gunning, A. P., Mackie, A. R., Wilde, P. J., \& Morris, V. J. (2009). Comparison of the orogenic displacement of sodium caseinate with the caseins from the air - water interface by nonionic surfactants. Langmuir, 25, 6739-6744. https:// doi.org/10.1021/la900241q.

Xu, L.-C., \& Logan, B. E. (2005). Interaction forces between colloids and protein-coated surfaces measured using an atomic force microscope. Environmental Science \& Technology, 39, 3592-3600. https://doi.org/10.1021/es048377i.

Xu, W., Mulhern, P. J., Blackford, B. L., Jericho, M. H., Firtel, M., \& Beveridge, T. J. (1996). Modeling and measuring the elastic properties of an archaeal surface, the sheath of Methanospirillum hungatei, and the implication for methane production. Journal of Bacteriology, 178, 3106-3112. https://doi.org/10.1128/jb.178.11.3106 3112.1996.

Yamada, Y., Konno, H., \& Shimabukuro, K. (2017). Demonstration of correlative atomic force and transmission electron microscopy using actin cytoskeleton. Biophysics and Physicobiology, 14, 111-117. https://doi.org/10.2142/biophysico.14.0_111.

Yang, G., Cecconi, C., Baase, W. A., Vetter, I. R., Breyer, W. A., Haack, J. A., et al. (2000) Solid-state synthesis and mechanical unfolding of polymers of T4 lysozyme. Proceedings of the National Academy of Sciences, 97, 139-144. https://doi.org/10. 1073/pnas.97.1.139.

Yang, H., Wang, Y., Lai, S., An, H., Li, Y., \& Chen, F. (2007). Application of atomic force microscopy as a nanotechnology tool in food science. Journal of Food Science, 72, R65-R75. https://doi.org/10.1111/j.1750-3841.2007.00346.x.

Ye, Q., Biviano, M., Mettu, S., Zhou, M., Dagastine, R., \& Ashokkumar, M. (2016). Modification of pea protein isolate for ultrasonic encapsulation of functional liquids. RSC Advances, 6, 106130-106140. https://doi.org/10.1039/C6RA17585F.

Yoshikawa, H. Y., Pink, D. A., Acevedo, N. C., Peyronel, F., Marangoni, A. G., \& Tanaka, M. (2017). Mechanical response of single triacylglycerol spherulites by using microcolloidal probes. Chemistry Letters, 46, 599-601. https://doi.org/10.1246/cl. 170014.

Zhong, J., Finglas, P., Wang, Y., \& Wang, X. (2019). Application of atomic force microscopy in food science. Trends in Food Science \& Technology, 87, 1-2. https://doi.org/ 10.1016/j.tifs.2019.03.030

Zhu, F. (2017). Atomic force microscopy of starch systems. Critical Reviews in Food Science and Nutrition, 57, 3127-3144. https://doi.org/10.1080/10408398.2015.1094650. 